Portland State University

PDXScholar

7-10-1995

\title{
Gaining State Response on Global Environmental Problem-Solving: Developing A State-centric Approach
}

Heather MacGregor Bothwell

Portland State University

Follow this and additional works at: https://pdxscholar.library.pdx.edu/open_access_etds

Part of the Political Science Commons

Let us know how access to this document benefits you.

\section{Recommended Citation}

Bothwell, Heather MacGregor, "Gaining State Response on Global Environmental Problem-Solving: Developing A State-centric Approach" (1995). Dissertations and Theses. Paper 4978.

https://doi.org/10.15760/etd.6854

This Thesis is brought to you for free and open access. It has been accepted for inclusion in Dissertations and Theses by an authorized administrator of PDXScholar. Please contact us if we can make this document more accessible: pdxscholar@pdx.edu. 


\section{THESIS APPROVAL}

The abstract and thesis of Heather MacGregor Bothwell for the Master of Science in Political science were presented July 10 , 1995, and accepted by the thesis committee and the department.

COMMITTEE APPROVALS:

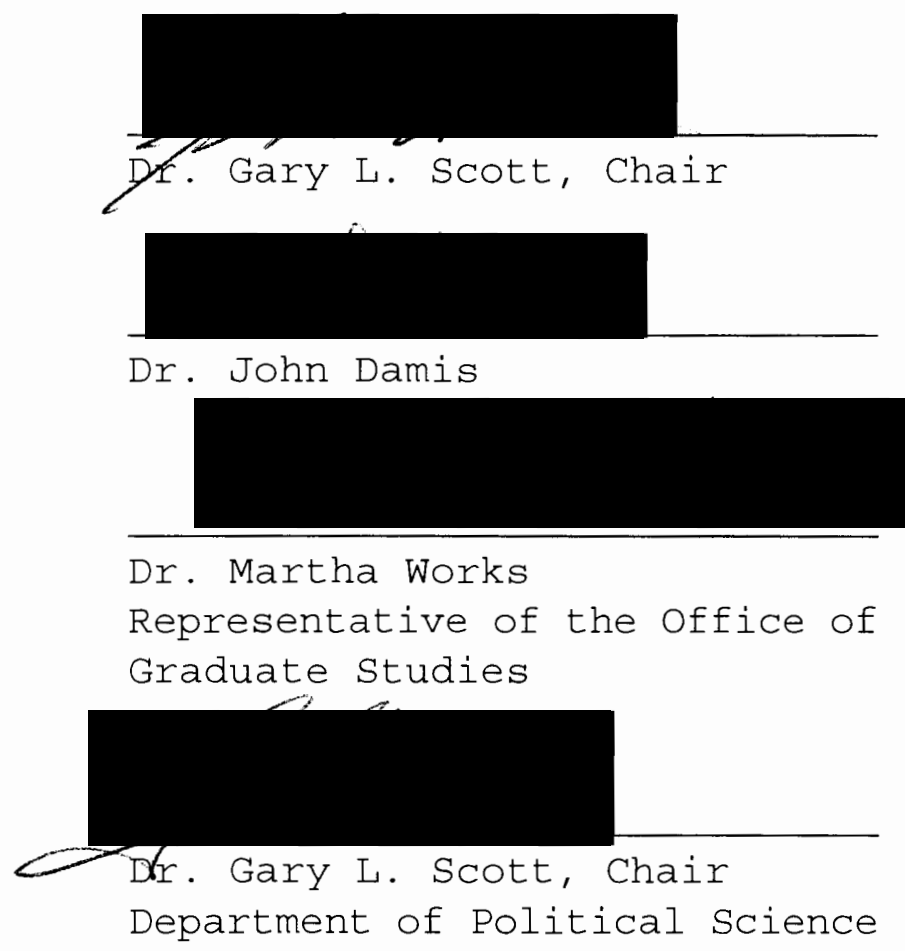

DEPARTMENT APPROVAL :

Department of Political science

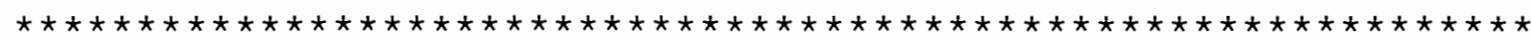

ACCEPTED FOR PORTLAND STATE UNIVERSITY BY THE LIBRARY

by

on

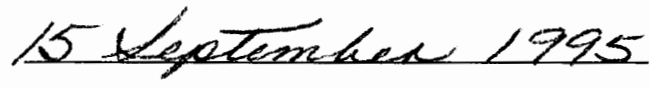




\section{ABSTRACT}

An abstract of the thesis of Heather MacGregor Bothwell for the Master of Science in Political Science, presented July 10, 1995

Title: Gaining state Response on Global Environmental ProblemSolving: Developing A State-Centric Approach

This study focuses on identifying the conditions which encourage or discourage international cooperation with regard to environmental problem-solving. In particular, the divergence between two key international relations theories, Environmentalism and Realism, will be examined in hopes of forging a rapprochement and stimulating research for a comprehensive theoretical approach to global environmental problem-solving. It is hypothesized that a state-centric political system is both a reality and an effective structure for environmental problem-solving, therefore an examination of state participation and the motivators and inhibitors affecting 
state response on certain environmental issues is conducted. In particular, this study hypothesizes that uncertainty can act as an inhibitor, and without the introduction of motivators can prevent states from participating in environmental problem-solving. A conceptual model of state courses of action is utilized to illustrate the potential of state participation and the development of a state-centric approach. 


\title{
GAINING STATE RESPONSE \\ ON GLOBAL ENVIRONMENTAL PROBLEM-SOLVING: \\ DEVELOPING A STATE-CENTRIC APPROACH
}

by

HEATHER MACGREGOR BOTHWELL

A thesis submitted in partial fulfillment of the requirements for the degree of

\author{
MASTER OF SCIENCE \\ in \\ POLITICAL SCIENCE
}

Portland State University

1995 


\section{TABLE OF CONTENTS}

PAGE

\section{SECTION I}

ENVIRONMENTAL PROBLEM-SOLVING AND ITS APPROACHES 1

INTRODUCTION 1

THE ENVIRONMENTALIST APPROACH 9

THE REALIST CRITIQUE

BRIDGING THE GAP 33

SECTION II

STATE PARTICIPATION IN ENVIRONMENTAL PROBLEM-SOLVING

INHIBITORS \& MOTIVATORS:

Creating Certainty or Uncertainty 46

Scientific Uncertainty \& the Need for Confirmation 52

Economic Uncertainty \& the Need for Reciprocity 54

Political Uncertainty \& the Need for Clear Rewards 57

\section{SECTION III}

REFLECTING INHIBITORS \& MOTIVATORS: A Model of state Response 62

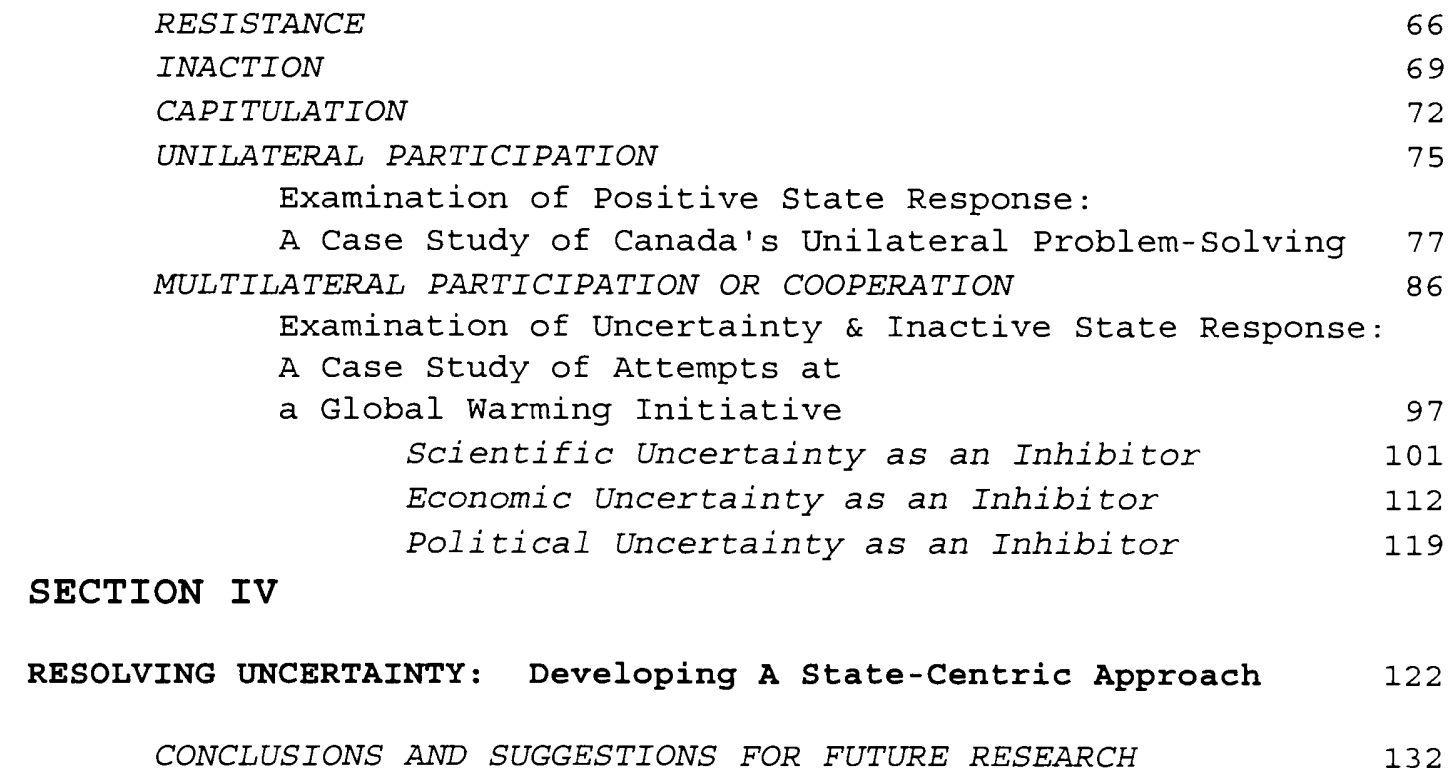




\section{ENVIRONMENTAL PROBLEM-SOLVING AND ITS APPROACHES}

\section{INTRODUCTION :}

In February, 1970, the largest class in the history of the Oregon State System of Higher Education started up at the University of Oregon. Called "Can Man Survive?," the environmental concerns class drew some 2500 students and had to be held in McArthur court, the huge indoor field house, because it was the only facility that could begin to accommodate that large a group.

Through the leadership of catalytic groups like the "Can Man Survive?" class, Environmentalism became a viable force not only in Oregon but across the United States and in many other countries throughout the world. And in the past twenty-five years, despite some political setbacks, the water and air supplies of many nations have 
improved, while recycling has become a major industry worldwide. Such significant national improvements have stimulated some attempts at international cooperation, but here the record is erratic; to date there have been only a few successful efforts at international cooperation on global-level environmental problems.

What is it about the approach of Environmentalism that has led to some notable successes in domestic environmental problem solving but has mostly failed to generate effective international cooperation in the environmental arena? Is there something about the philosophy itself that is antithetical to cooperative efforts among nation-states? This study is focused on identifying some of the reasons for the relative lack of international cooperation on environmental problems, and also on presenting some ideas which might help stimulate greater cooperative efforts in the future.

In particular, the divergence between two key 
international relations theories, Environmentalism and Realism, will be examined for their differences and a plan for harmonizing the two will be detailed through development of an environmental problem-solving approach which combines the appeals of Environmentalists and the state-centric political structure most accurately described by Realists. It is hoped that this examination will help forge a rapprochement between the two schools and stimulate research for a comprehensive theoretical approach to global environmental problem-solving.

This study further focuses on identifying the conditions which encourage or discourage international cooperation with regard to environmental problem-solving. This paper seeks to refute the argument that states are remiss in addressing environmental problems. Rather, it would appear that states are likely to act on environmental issues where certain conditions are present ("motivators"), and when certain obstacles ("inhibitors") 
are removed. Specifically, this study hypothesizes that uncertainty can act as inhibitor in environmental problemsolving and can manifest itself in three important areas: scientific bases, economic outcomes and political outcomes. Thus, without the introduction of motivators, uncertainty can prevent states from performing a rational cost-benefit analysis in favor of participating in environmental problem-solving. Accordingly, this paper will examine state participation in general and identify five principal types of state responses to environmental problems which are presented in relation to levels of uncertainty. Following this discussion a conceptual model will be utilized to correlate the effects of the introduction of motivators and inhibitors with the typology of state responses. This study postulates that these so-called motivators and inhibitors are not static factors, but can be employed dynamically to either encourage or discourage state participation. Therefore, 
in the final section two case studies will be presented to illustrate the possibilities of employing the model in a state-centric approach to environmental problem-solving. It is hoped that the analysis will contribute to both an understanding of and possible development of a statecentric approach to re-solving environmental problems.

The need for global environmental problem-solving techniques is increasing. With the end of the cold war, much of the focus on military security has shifted to other areas, including the environment. However, despite an evolving concern over environmental degradation, the chasm between awareness and political action is growing. This inertia has generated considerable criticism, which asserts that current political structures are inadequate to attempt environmental problem-solving. However, while such criticism may be justified, given states' apparent inaction on certain environmental issues, it is premature. To date there have been few attempts to address 
environmental issues utilizing current political structures. Rather, there continues to be a lack of inquiry into effective methods for achieving solutions to environmental concerns. Attempts to forge connections between problems and policies, structures and solutions, and actors and attitudes have been consistently inadequate.

In traditional areas of policymaking such as national security, there exists an extensive discourse on international relations theories which argue the pros and cons of various approaches to contemporary concerns. Most notably, since World War II various types of Realists ${ }^{\text {l }}$ have been represented as the dominant voice in this discussion. Recently, however, there has been a resurgence of Idealist ${ }^{2}$ tenets, and increased discussion of the role of alternative ideologies in the arena of international politics.

Despite a considerable amount of scholarly discussion 
regarding specific environmental concerns, though, there is a distinct lack of literature regarding international relations theory in environmental policymaking. Given the dominance of Realism in addressing more conventional areas, it is particularly surprising to have a paucity of Realist discussion over this key concern. It is especially significant, given the state-centric focus of Realism, that state-centric discussions of environmental policymaking are absent. Further, although the shortage of Realist-based environmental discussions has spurred Idealist censure, Idealists have not offered much in the way of alternative policymaking discussions, except approaches which ignore current political structures.

We are faced then with a somewhat unusual situation, in which Environmentalism has been a growing force for 25 years, and numerous nation-states have been confronting and resolving environmental problems for the same time period, and yet no substantial body of Environmentalist 
policymaking literature has evolved in concert with these other developments. Because the increased concern over the environment has not engendered a comprehensive theoretical discussion and the success of environmental problem-solving remains sporadic, varying from issue to issue, this study seeks to initiate a dialogue over approaches to environmental problem-solving in hopes of generating further research. Therefore, this paper examines the divergence between existent environmental concerns and nation-state responses to those problems, and asks how to develop effective environmental problemsolving techniques. Where development of problem-solving strategies is the goal, this analysis further seeks to harmonize the current approaches to environmental problemsolving with the policy-making needs of states.

Because this paper also hypothesizes that a statecentric political system is both a reality and an effective structure for solving environmental problems, it 
is believed that any comprehensive attempt to address environmental problem-solving must include a discussion of current political structures, notably the role of the state, in its analysis. Therefore, this paper ultimately seeks to position environmental problem-solving within a state-centric approach, thus placing the arguments of Environmentalists within the context of Political Realism. In this way, it is hoped that further research into environmental problem-solving will produce greater incidences of state response and more substantial results from those responses.

\section{THE ENVIRONMENTALIST APPROACH}

The development of environmental awareness can be viewed as the first step in a process which can lead to global environmental problem-solving. This is largely because, although it may be widely unrecognized by its advocates, 
Environmentalism has gone from coffee shop talk to prominent political argument. Therefore, the history of Environmentalism is also the history of incremental state awareness and the beginning of state consideration of Environmentalist claims. Environmentalism is the challenge of Idealism applied to environmental concerns. In particular, it advocates placing the needs of the environment above the short-term needs of the human population. As such, Environmentalism "challenges certain features of almost every aspect of the Western democratic capitalist culture - its motives, its aspirations, its institutions, its performance, and some of its achievements."3 Environmentalism is the outgrowth of the conservationist movement that began in the late nineteenth century and was associated with Transcendentalism. ${ }^{4}$ Although ecology was influential in the development of the conservation movement, ecological awareness was missing from the public consciousness until after the 1950s.5 
Politically activated in the 1960s, Environmentalism was fueled by accounts of widespread industrial pollution, and became known as the ecology movement. ${ }^{6}$ In 1962, Environmentalism gained support through public awareness of environmental issues. The publication that year of Silent Spring by Rachel Carson brought about far-reaching recognition of the ecological movement, and became the hallmark of modern Environmentalism. ${ }^{7}$ Finally, the application of philosophy to Environmentalism brought about its maturation into a contemplative perspective that moved beyond the Iimited inquiry of social activism and technical management discussions. ${ }^{8}$

Two definite and divergent branches of Environmentalism developed from the association of philosophy to ecological thought: Ecocentrism ${ }^{9}$ and Technocentrism. ${ }^{\text {io }}$ Technocentrism places faith in technology to solve environmental problems, and therefore, advocates a scientific revolution. Ecocentrism is more radical; it rejects the 
Technocentric nature of conservationist approaches which seek to save natural resources for economic gain. In opposition to that valuation of environmental assets, Ecocentrism attempts to define a bio-centric view which values nature for its own sake. As such, Ecocentrism is most closely linked to the Transcendentalist tenets of a bioethic ${ }^{11}$ Ecocentrism is also known by some Environmentalists as Deep Ecology. ${ }^{12}$ Deep Ecologists adhere to a philosophy that begins with the world in a state of crisis where shared values in a more earthfriendly way of life lead to a better lifestyle. Specifically, Deep Ecology rejects the anthropocentric view of the world inherited by other dominant ideologies, e.g. capitalism. ${ }^{13}$ The publication of Limits to Growth ${ }^{14}$ in 1972 is an excellent example of the Ecocentric approach .

Environmentalism is inherently opposed to a Realist theory of international relations, i.e. "a state-centric 
tradition which accepts a world divided into independent sovereign states as being the normal if not permanent condition of international society."15 Environmentalist perspectives argue that the state remains a serious obstacle to environmental problem-solving, because it hinders the realization of a comprehensive global approach. Instead, Environmentalism holds that international institutions must accept collective responsibility for decision-making regarding global concerns such as: military security, economic well-being, human rights issues and, of course, environmental protection. ${ }^{16}$ This transnational viewpoint rejects the notion that "traditional security thinking and political Realism,"which are based on ideas of sovereignty and territory, can adequately address the needs of the environmental security threat. ${ }^{17}$ Therefore, Environmentalists believe global solutions are "unlikely products of states acting alone, or in cooperation with 
one another."18 Many Environmentalists indicate that states represent inappropriate entities for resolution of environmental problems, ${ }^{19}$ premising this theory on two counts: first, states are considered to be self-interested bodies; ${ }^{20}$ second, state boundaries are not a useful demarcation of environmental issues. ${ }^{21}$

In his famous essay, "The Tragedy of the Commons," Garrett Hardin contends that avoidance of the impending tragedy of humanity requires mutual coercion to limit freedom.22 From Hardin, one of the first principles of Environmentalism was constructed, the view that the earth must be considered as a whole or commons. ${ }^{23}$ This Environmentalist argument is embedded in the purported existence of an interdependent relationship, one between human beings and the environment; this relationship must, according to Environmentalists, be addressed by political and social systems and is the cornerstone of the Environmentalist approach to problem-solving. ${ }^{24}$ Therefore, 
most Environmentalist perspectives contend there is a need for new diplomacy and for new institutions and regulatory regimes to cope with the world's growing environmental interdependence, a phenomenon where the environmental problems of one state affect all others. ${ }^{25}$ Therefore, "the accepted definition of the limits of national sovereignty as coinciding with national borders is obsolete."26 Further, because the state is seen by Environmentalists as inherently inadequate to address environmental dilemmas, their perception implies that ecological peril is one of several macro-political trends which has "chipped away the state's supremacy."27

Environmentalists also have adopted interdependence theory as a political construct for their approach. Political interdependence theory asserts that today's relationships among nations reflect a greater interconnectedness and a common reliance upon each other's actions, a development due largely to increased 
interactions among states and members of states. ${ }^{28}$ Many types of political theorists conclude that relationships among states exist on many levels: those among governments, those among corporations, those among nongovernmental organizations, and those among individual citizens. ${ }^{29}$ However, Environmentalists appreciate the value and connection of other-than-governmental relationships far above those of state. Environmental interdependence theory attests: as states interact more frequently, the importance of other associations increases. ${ }^{30}$ Accordingly, Environmentalists contend that a natural systemic evolution is occurring, which dictates that the present structure of governmental relationships will become less and less significant in the international system. ${ }^{31}$

Since one Environmentalist assumption holds that the nation-state is ineffective in the environmental problemsolving process, their formula for the future will necessitate an alternative systemic construction. 
Environmentalists advocate the following: international organization empowerment, steady-state economic modeling, local environmental revolution, equitable distribution of wealth, scientific dependence, and, of course, one-world government, ${ }^{32}$ i.e., the "one earth perspective. ${ }^{13}$ At one end of the spectrum, Environmentalism re-conceptualizes the Marxist, Liberalist tenets of equity and emancipation, advocating a "revolution from below" through which proponents of the "Think Globally, Act Locally" perspective feed a movement which forces change into the system. ${ }^{34}$ This movement is developed on the self-reliant community model that takes its doctrine from Transcendentalist ideas. At its most benign, this division is seen to appeal to a decentralized definition of management techniques; at its most radical, it is aligned with extreme post-industrial tribalism where nonhierarchical communes reflect an eco-friendly way of life. ${ }^{35}$ In the form of Ecocentrism, Environmentalism seeks 
to "dismantle or bypass the modern nation state and establish decentralized, autonomous, human-scale communities." 36

At the other extreme, Environmentalism presents the desire for global enforcement mechanisms, which should be developed through a universal network or organization. ${ }^{37}$ It is this latter appeal that is often seen as petition for one-world government. World government advocates recommend universal control of all international policymaking. The Environmentalist justification for this global-centric approach lies in an attempt to interrupt the "inertial tendency to remain unresponsive to changing security needs."38 Environmentalist world government champions assert "it is essential to develop a principal world policy designed to serve the human interest as opposed to national interests;"39 any national perspective becomes partisan from the global one. ${ }^{40}$ Therefore, Environmentalists state that universal solutions, 
environmental and otherwise, require universal governance. ${ }^{41}$ The world security concept is inspired by Environmentalist recognition of a range of new environmental perils that transcend national borders and exceed the reactive capabilities of nation-states. And it is informed theoretically by a range of suppositions that emphasize new growth of global interdependence and the possibility of international cooperation. ${ }^{42}$

As such, the locus of Environmentalist theory concentrates on an attack against statehood. The precepts of such an attack lie in the Environmentalist assumption that the needs of the state and those of the global commons are antithetical. Principally, Environmentalism asserts that the goals of the national interest and national security ultimately degrade the commons, while the authority of sovereignty and the philosophy of global equity are opposed. ${ }^{43}$ Further, the legitimacy of the state is questioned, based upon the perception of behavioral 
constraints inherent within the current system. ${ }^{44}$ As such, Environmentalist perspectives prescribe that states must alter their behavior from one which exhibits true sovereignty to one which illustrates the natural interdependence of actors both environmentally and politically. ${ }^{45}$ And, because Environmentalists see little within the current system which indicates that states will achieve this altered behavior, their focus on human interests causes them to advocate alternate political structures.

Ultimately, Environmentalists advocate dramatic changes in the system, with the goal of achieving reduced statecentrism. ${ }^{46}$ Through universality, equity and intervention, ${ }^{47}$ Environmentalists attest, global policies must be implemented and enforced. In its most radical form, Environmentalism seeks to establish the environment above any political or social institution. 


\section{THE REALIST CRITIQUE}

Despite the emergence of Environmentalism into mainstream politics, its theories have yet to be translated into comprehensive scholarly writings in political science. The need to define and develop an ecological political theory was recognized as early as 1973. ${ }^{48}$ Then, and now, fledgling ecological theories relied on notions of systemic alteration, a concept with serious drawbacks given the dominance of the nation-state system since the Treaty of Westphalia in 1648. Further, Environmentalism advocates a diffuse approach to environmental problem-solving; the majority of Environmentalist literature merely deliberates the quantity of existing environmental problems requiring solutions; rarely is there a comprehensive discussion concerning what steps ought to be taken to effectively address the problematique. ${ }^{49}$ In one respect this is a 
tribute to the effectiveness of Environmentalism in capturing the attention of analysts and policymakers; in another, it is a statement about the need for further discussion of the role of the state and Realism in relation to emergent theories of Environmentalism. Much of Environmentalist literature is devoted to either attacking Realist theories of world politics or asserting that the state no longer holds a legitimate existence. ${ }^{50}$ However, it is not 'an adequate deliberation merely to make these claims without incorporating a comprehensive look at the relationship, or lack of one, between Realism and Environmentalism. Further, the absence of this discussion in the face of this principal dichotomy weakens both international political and environmental theory; in addition, it may inhibit development of an adequate methodological approach for effective environmental policymaking

Although there is some disagreement about the parameters 
for environmental politics and international political theory, "the disputed ground," as Ann Hawkins calls it, provides a place for political inquiry. ${ }^{51}$ Ultimately, political analysts need to develop comprehensive methods of determining environmental policy and environmental problem-solving strategies. These techniques will necessarily incorporate some of the arguments of Environmentalists; however, one must increase the realm of the discussion to ask: "How and how well, does the political system respond, or can be made to respond, to the accelerative spoilation, depletion and pollution of our physical habitat?"52 There are several questions within this larger one. First, what are the deficiencies concerning environmental problem-solving at the systemic level? Second, what is the role of the state in environmental problem-solving? And, third, can an agreement be found to bridge the gap between Environmentalist claims of global catastrophe and Realist 
notions of international relations?

Kenneth Waltz reminds us that the international system, by most accounts, is still a state-dominated structure. As such, theories of Realism remain the most pervasive perspective in international politics. ${ }^{53}$ There are many sub-theories of Realism. In particular, structural Realism ${ }^{54}$ and Neorealism have further developed the original premises of Classical Realism. ${ }^{56}$ It is beyond the scope of this paper to discuss the various types of Realism in-depth; however, the basic tenets of Realist thought, held in common and based upon a state-centric tradition, are evidenced throughout. Accordingly, references will not be made to the distinctions within the Realist paradigm, but will, in fact, refer to the major conflict between Realism and Environmentalism.

Realists assert that interdependence, as presented by Environmentalists, is not much of a theory upon which to base altering the state-centric control of international 
relations. The problem with interdependence lies in its definition or the lack of a singular, comprehensive one; "interdependence is a concept before it is a fact, and unless the concept is defined, we cannot intelligibly discuss what the present condition of interdependence is, whether it has been increasing, and what its political implications may be. ${ }^{57}$ Thus, despite the use of ubiquitous phrases such as "the shrinking planet, global village and international interdependence," 58 there is little evidence to suggest that the world must be taken as a whole. Rather, Realists submit that solutions to international problems continue to depend on national policies, and any approach to problem-solving must include the primary political actors, i.e. states. ${ }^{59}$

Still, Realists do not presume that states are indifferent to the actions of others. On the contrary, Realism suggests that states act and react to others, hence the need for self-help measures to contend with 
those situations in which the actions of one state have negative consequences for the other. However, the anticipation of exchanges between states that can affect policy decisions does not automatically imply situations of interdependence as defined by Environmentalists. As Arthur stein illustrates, the idea that nations may exhibit a greater interconnectedness does not necessarily imply a mutual dependence. ${ }^{60}$ In accordance with waltz, Stein argues that interdependence may actually be the dependence of less powerful states upon the actions of greater powers. However, the opposite could scarcely prove true. Great powers may actually benefit from a theory of interdependence. It is the continued play of power-politics which fuels the Realist argument that interdependence is a perceptual construct which may only exist in limited situations. As such, "without necessarily denying such tendencies as economic interdependence or uneven development, Realists could 
argue that power-politics structures would refract and limit the effects of these tendencies in ways securing the structures themselves." 61

The Realist thesis focuses on the international system's primary political actors and, therefore, necessarily incorporates power politics into a theory of international relations. The recent emphasis on purported political interdependence presupposes situations of equality and dependence that have yet to be proven existent. While arguing against this definition of interdependence, Realism does acknowledge that states are affected by the actions of others. For example, Keohane, a Neorealist, suggests three types of "interdependence" that are manifestations of state-to-state interaction and response.

Keohane's first example is defined as instrumental interdependence. In this case, actors are said to be interested in the welfare of other actors insofar as "others can take action that affects them."62 Secondly, 
situational interdependence occurs when other actors' welfare can improve the first actor's situation.63 Examples include economic actions such as a recession which can adversely affect the economies of other states. Finally, empathetic interdependence is defined by Keohane as the acting in the benefit of others, simply for the sake of doing so. ${ }^{64}$

Although waltz would agree that states often act in manners such as these, rather than acting strictly out of self-interest, he would hesitate to call these actions interdependence, especially as the term is utilized by Environmentalists. In the first case, instrumental interdependence appears to describe self-help behavior. States are interested in the actions of others, because they see those decisions as affecting themselves. Thus, they react with policies which minimize the adverse impact of others' policy decisions. Therefore, instrumental interdependence does not describe a situation where one 
state is dependent upon the actions of another to formulate its own policy decisions as is implied by Keohane; rather it describes the process of arriving at a rational cost-benefit analysis based upon the actions of others.

Similarly in situational interdependence, actors seek to maximize the benefits of others' actions, and may even attempt policy coordination with those actors to achieve the most desirable outcome. Again, however, capitalizing on a situation where one actor's actions can benefit the first's does not indicate that either actor is dependent on the other for determining its own policy preferences. And, in empathetic interdependence, Keohane describes a situation in which states act out of empathy or moral insight. Although in the past, strictly Classical Realists have suggested a Hobbesian world where states act solely out of the desire for power, i.e. power-seeking behaviors, newer Realist constructs have not discounted 
state actions on the basis of morality. The latter is often thought to be a type of order-seeking behavior ${ }^{65}$, where broadly-defined interest in preserving the international system as a whole, keeps states from eliminating any actor from the system. As such, states often act in ways which benefit others and ultimately benefit themselves. ${ }^{66}$ None of Keohane's interdependence definitions are contradictory to Realist theories of state action, or conflict with state-centric problem-solving. However, neither do they accurately reflect a situation which is interdependent and therefore do not advance Environmentalist arguments for cooperation based upon that notion.

It would seem that where it is intended to illustrate a mutually dependent situation that encourages actors to cooperate either to alleviate a bad, or evenly distribute a good, interdependence is not a firmly established concept, and from the Realist point-of-view is not a 
motivator for gaining state participation in cooperative arrangements. The Realist-based concept of interdependence as sensitivit $y^{67}$ or vulnerability ${ }^{68}$ may play a role in bringing states to the table. Sensitivity, or the liability to costly effects imposed externally before policies are altered to attempt to modify the situation, ${ }^{69}$ and vulnerability, or the liability to costs imposed from outside even after policies are altered, ${ }^{70}$ create the perception of the need to act in order to minimize negative outcomes. The levels of sensitivity or vulnerability, however, may be unequal as some states are better-equipped to deal with certain situations. If all member states perceive that there is some benefit associated with participating in a cooperative arrangement, or some cost associated with not doing so, sensitivity or vulnerability may motivate state participation. Again, however, the perception of sensitivity or vulnerability to a particular issue is not 
political interdependence unless states also perceive reciprocity, or an even exchange of costs and benefits, to be associated with the arrangement. ${ }^{71}$

Thus, the Realist viewpoint does not suggest that states are impervious to environmental degradation of the global commons. However, it does refute Environmentalist claims which cling to a "domino theory"72 of interdependence. Nation-states do not perceive that all occurrences of degradation will damage them directly, thus necessitating a response. ${ }^{73}$ Rather, states perceive that they are susceptible to the actions of others, which may motivate those actors to participate in cooperative arrangements. The use of the term interdependence to describe political, economic or ecological situations where mutual dependence exists is neither agreed upon nor appears to act as a catalyst for state participation in environmental problemsolving. Further, despite the attempts of some Realists from differing perspectives to qualify the idea of 
interdependence, perhaps initiating some common ground with Environmentalists, the notion of interdependence remains varied and of little use to policymakers. Therefore, as a construct which in the eyes of Environmentalists mandates altering the political control of the international system, the interdependence argument is inadequate. Only as the perception of a greater connectedness or interrelatedness does the idea of interdependence gain meaning and become useful in bringing about awareness of state susceptibility to environmental degradation.

\section{BRIDGING THE GAP}

Environmentalism remains a truncated ideology, despite several decades of intense effort on certain political issues. Albeit that Environmentalism is an evolving set of political ideas, Environmentalists "must develop a clear and consistent position on the full range of 
political and social issues."74 several of the Environmentalist proposals can be adapted to fit the current Realist structure of the international system, but it is clear that recent Environmentalist commentary finds the state inadequate to address the problematique of environmental problems. ${ }^{75}$ Many Realists agree that "the time has come to give certain world interests primacy over various national, local and special interests."76 However, this does not auger the demise of a Realist world polity, rather it illustrates the need for Environmentalists to develop an effective appeal to Realism. Instead of promoting structural change, Realists seek to develop problem-solving strategies within the constraints of the current system. Thus, this paper intends to suggest that global environmental interests might be better managed through increased nation-state participation, and consequently Environmentalists need to address those entities through a state-centric appeal. 
It is the Realist perspective that Environmentalism commits the "is, ought" fallacy. ${ }^{77}$ By attempting to address the international system that currently is in existence, with approaches of the way it ought to be, Environmentalism is not confronting the issue of problemsolving. It is as though in accepting the structure of the Realists, Environmentalists believe that their arguments will be discounted. But will policy goals be undermined by focusing on the existent system? On the contrary, "moral values and policy goals can be well served, even best served, by putting them aside and proceeding detachedly long enough to enlarge empirical understanding of the obstacles that hinder realization of the values and progress toward the goals."78 The dominant points of the Realist thesis are hardly outmoded by newer theories which advocate alternate systemic constructions, e.g. Idealism. Although today there exists a system which includes other transnational actors, such as international 
organizations, the Realist perspective does not deny this fact. Rather, it merely suggests that these actors are secondary to states. Further, it intimates that international associations and bodies are inventions of states, developed because they are useful to sovereignties. As such, the existence of other actors is dependent upon the legitimacy of states. In addition, there is much evidence to suggest that the state-centric international system is not being discarded in favor of another construct. Initially, there is the issue of sovereignty, which dictates that only states are guaranteed a certain legal status under international law; one that is denied to other global actors. ${ }^{79}$ Secondly, states are the law-making entities under the system of international law. ${ }^{80}$ Although there are different sources of law, states ultimately hold the right to ascribe to a set of laws, or to prevent those laws from being effective in the system. ${ }^{81}$ As such, it seems highly improbable that 
other types of international bodies could replace the authority of states. And, if states are the primary political actors, then it is inappropriate to formulate solutions to environmental problems without addressing those entities.

The current Environmentalist argument focuses primarily on creating alternatives to nation-state dominance in the international system, instead of determining methods for gaining state participation. While this argument may represent some future structural method for addressing environmental dilemmas, it is unsuitable for the contemporary system; the obstacle to these techniques remains that sovereignties are not interested in relinquishing their position as primary actors. Furthermore, concentrating on alternatives may contribute to the continued lack of effective measures for addressing environmental issues. The problem-solvers of this world remain nation-states, and accordingly, problems 
must be couched in terms to which states can respond. Without framing the question in a state-centric approach, operative solutions are unlikely to be developed, and without further development of theories of environmental policymaking, the Realist argument exudes powerful grounds for the failure of the Environmentalist approach. It is the crux of the Realist stance that problem-solving methods must be directed toward the political actors of the current international system. Any other approach will ultimately be constrained by the actions of those actors, and is, therefore, doomed to failure. Thus, Realism serves as a reminder; environmental problem-solving techniques which do not address states, may be consigning themselves to inadequacy.

Solving the problematique of environmental concerns is a difficult task. In summary, the deficiencies concerning global environmental problem-solving include the following. In addition to the unreasonable approach of 
Environmentalism, the process has been further hampered, it seems, by the incongruity between the state system best understood by the Realist perspective and the focus of Environmentalist appeals for action. Thus, the development of global environmental problem-solving strategies is often stymied, while current stop-gap measures are deficient in their approach. Furthermore, the pervasive nature of Realist theories causes Environmentalist appeals to seem fairly ineffective. The role of the state has been neglected by Environmentalism, and should be addressed.

Despite the above, it is believed that the breach between Environmentalism and Realism can be mended; by recognizing that the Realist thesis does not reject the need to address environmental problems, Environmentalists can modify their approach to include states. Were this to occur, the possibility of developing environmental problem-solving strategies at the systemic level looks 
hopeful; the catalyst for change lies in the evolution of a state-centric approach, rather than in an unrealistic attempt to eliminate nation-states. Environmentalists do not have to accept the present condition of the ecosystem, in other words, but they do have to accept the present political structure. 


\section{STATE PARTICIPATION IN ENVIRONMENTAL PROBLEM-SOLVING}

Realism and state-centric approaches to environmental problem-solving do provide optimism for Environmentalist concerns. Despite the criticism of Environmentalists, there are many examples of active state participation in environmental problem-solving. Furthermore, states are likely to continue to participate under certain circumstances; only three decades ago concern about the deteriorating state of the earth's environment was confined largely to the scientific community and groups of environmental activists. Since the 1960s, environmental concerns have risen rapidly to prominence as public issues, and are now leading policy problems on both national and international agendas. Environmental issues such as acid rain and ozone depletion have gained the attention of states; "both issues which were dismissed as 
scare-mongering at the beginning of the decade [1980s] and by the end of the decade, were recognized as major threats justifying belated and expensive action."82 Further, despite the evolutionary approach of states to environmental problem-solving, there have been some notable successes in the environmental field; for example, nuclear weapons are not being tested in the atmosphere, less hazardous waste is being dumped into the oceans, and significant progress has been made on issues such as acid rain and ozone depletion.

As early as 1867, compacts between states indirectly included questions regarding the environment, through discussion of issues such as fishing rights.83 In 1909, the US and Canada signed the historic Boundary Waters Agreement. This may represent the first recognition of the transboundary nature of the environment, and consequently, of environmentally-degrading agents. The principle of transboundary control was further established 
by the benchmark decision in the Trail smelter case of 1941 in which "a specially convened tribunal ruled that Canada should compensate the United states for damages to orchards in the state of Washington that were caused by air pollutants drifting over the border from a smelter in Trail, British Columbia."84 These and many other examples are illustrative of state initiation of environmental problem-solving, seen in the generation of international agreements. Furthermore, the rate of adoption of environmental treaties has accelerated during recent decades: "only twenty were concluded between 1921 and 1959, twenty-six during the 1960s, forty-nine during the 1970s and forty-eight during the 1980s."85

In fact, following the end of the Cold War, many nations began to regard "ominous environmental trends as being one of the primary sources of insecurity for both current and future generations." ${ }^{86}$ Evidence of state participation in environmental problem-solving directly conflicts with 
Environmentalist claims that states are inadequate to address environmental problems because they lack the impetus to initiate problem-solving. The fact is, states are willing to participate in environmental problemsolving under the right conditions. Many states, "including those most responsible for existing pollution, have demonstrated a willingness to cooperate" 87 on environmental issues. And, as illustrated by the increase in number of environmental agreements, states have been accelerating their efforts to create and strengthen international regulatory mechanisms that will slow the pace of environmental degradation and change. The fact states do participate in environmental problem-solving efforts, however, does not refute Environmentalist claims of inaction on certain issues. Thus, determining the factors that motivate state participation can provide a bridge between Environmentalist appeals and a Realist theory of international politics. Without such an 
inquiry, Environmentalist petitions will continue to be "hit-and-miss." That is, sometimes such an appeal will coincide with a pre-conceived state interest, and will engender participation, but alternatively, an entreaty may also generate inactivity or worse, resistance. This possibility could upset the problem-solving process as it currently exists and further the rift between states and Environmentalists.

In order to gain state participation in environmental problem-solving, three conditions appear to be necessary. First, states must be able to perceive the existence of an environmental problem which requires state involvement for resolution. Second, the state must be able to discern that the problem could have a state-centric consequence; in other words, states must perceive that the result of the problem will have a direct effect on the state itself. And thirdly, the state must have sufficient self-interest to respond to the problem, i.e. the state must find that 
the benefits of response outweigh the costs. It is this latter condition that is the most difficult to determine and that is frequently thwarted by inhibiting factors which produce negative perceptions or uncertainty. For this reason, the cost-benefit issue needs to be addressed by Environmentalists more than any other topic. The following section presents elements intended to assist in the development of such an approach. The concepts of motivators and inhibitors, mentioned previously, are central to the discussion.

\section{INHIBITORS \& MOTIVATORS :}

Creating Certainty or Uncertainty

This section presents a conceptual model which relates inhibiting and motivating factors to a continuum of possible state responses to environmental problems. The goal is to contribute to an understanding of and possible development of a state-centric approach to resolving 
environmental problems. The five principal courses of action which states can take to address environmental problem-solving are: resistance, inaction, capitulation, unilateral participation and multilateral participation or cooperation. The conditions under which each course of action becomes a logical policy option vary dependent upon the costs and benefits involved; therefore, an examination of each may be helpful in establishing a state-centric approach for environmental problem-solving.

Initially, in a given situation there exist factors which can either encourage or discourage one of the five potential courses of state action; these have been labeled motivators and inhibitors. Further, perhaps these factors can be also promoted or suppressed in order to facilitate the outcome of participation between and among nations on a given environmental problem. Therefore, it is important to conduct an examination of the decision-making process, especially inhibitors preventing participation and 
motivators encouraging participation, with the objective of clarifying as precisely as possible the conditions under which state response may occur.

The introduction of uncertainty into the environmental problem-solving process often appears to stymie state participation. Uncertainty results when insufficient information causes actors to become unclear about their own policy goals. Primarily, uncertainty prevents clear understanding of expected outcomes in the decision-making process, thereby preventing a definite and prescribed course of action. Realists postulate that states exist in an anarchic world system and interact based upon selfhelp strategies. One pattern exhibited by states through this continued interaction is the desire to maximize gains; ${ }^{88}$ states are seen to perform a rational calculus whereby the benefits of participation must outweigh its costs. However, uncertainty is problematic for engendering state participation because it prevents a clear definition 
of state preferences and manifests the perception of risk. ${ }^{89}$ Thus, uncertainty in the problem-solving process can cause the rational calculus to become ineffectual.

Axelrod has demonstrated that although the anticipated behavior of states is one where they act to maximize gains, states often cannot react in this manner when there is uncertainty in the cost-benefit analysis. ${ }^{90}$ Instead, the uncertain situation often creates an indifference to the whole process as preferences become increasingly difficult to determine. ${ }^{91}$ This behavior can be illustrated through probability theory using Theil's example: A state E faces a decision regarding alternatives ( $A, B ; p, 1-p$ ) where $\mathrm{p}$ is a number between 0 and 1 , giving the outcome of A with the probability of $p$ or $B$ with the probability of 1-p. ${ }^{92}$ In such circumstances, the decision-maker is left with a choice which is uncertain: either the state will receive $A$ or $B$, but cannot be sure of which. ${ }^{93}$ As such, decision-making steps such as ranking, comparability and 
transivity become indeterminate, causing the development of concrete preferences to be difficult. ${ }^{94}$ This predicament is further complicated by the addition of many actors, the typical situation in multilateral agreement negotiations, for if State $E$ cannot determine its own preferences with any surety, it cannot be expected to communicate or negotiate upon this basis.

The fact that environmental problems are so complex that they have been described as a problematique makes this type of problem-solving particularly difficult. It is characteristic of environmental problems that they are "multiplicitous and unfocused,"95 and consequently, uncertainty is a continual factor in the environmental problem-solving process. For this reason, the potential ramifications of environmental problems, and of their proposed solutions, often generate perceptions of risk on the part of states. Therefore, it is important to keep in mind the uncertainties and side effects in environmental 
policymaking, which can stifle state participation and attempt to develop methods of overcoming them. ${ }^{96}$

This study hypothesizes that uncertainty in environmental problem-solving can manifest itself over three important areas: scientific bases, economic outcomes and political outcomes. As will be illustrated, overcoming uncertainty in each area may be critical to the establishment of ongoing state participation. Depending upon the type of environmental issue being deliberated, one type of uncertainty can assume preeminence over another. Further, uncertainty in one realm can contribute to indecision in another. Finally, it seems probable that issues with high levels of uncertainty in all three areas are unlikely prospects for gaining positive state participation and will result in non-participation. 


\section{Scientific Uncertainty \& the Need for Confirmation}

Lack of a scientifically confirmed environmental threat to states complicates attempts to gain their participation in environmental problem-solving. Although many agreements are initiated based upon their inherent utility, these are usually uncomplicated instruments with clear benefits and minimal costs associated with state participation. Examples of such cooperative interactions include agreements regarding human health standards, mail service, transportation regulations and trading practices. ${ }^{97}$ However, because of the evolving perception about the importance of environmental problem-solving and the ramifications that environmental outcomes may have upon states, a clear perception of threat regarding specific environmental issues is key to the development of a perceived tangible state-centric consequence necessary for state participation. 
States may have awareness regarding a specific environmental problem, but few will perceive the need for state involvement without seeing the problem as directly affecting them, most often as a perceived threat to national interests. And, because states are selfinterested, concerned minimally about their survival and maximally about their position in relation to other states, ${ }^{98}$ evidence of threat to national interests is a strong motivator. In fact, the greater the perception of threat, the less the need for certainty about specific outcomes and the lower the concern about relative gains. For example, in the ozone depletion issue, the perception of a health hazard was great enough that it overrode the need for knowledge about specific population numbers involved and the need to establish whether one state would incur more health hazard than other states. ${ }^{99}$ 


\section{Economic Uncertainty \& the Need for Reciprocity}

Lack of reciprocity, or the absence of an even exchange, is another barrier to participation in multilateral situations where a large number of actors is involved. ${ }^{100}$ Reciprocity "refers to exchanges of roughly equivalent values in which the actions of each party are contingent on the prior actions of others in such a way that good is returned for good, and bad for bad."101 While not confined to economics, reciprocity is especially important when economic uncertainty exists. High costs are often perceived as the outcome in many problem-solving efforts. Reciprocity in the form of a near-equal distribution of those costs can reduce economic uncertainty. In particular, cases where public goods, (i.e. goods which are available to all members) are at stake, "there are substantial incentives to behave as a 'free-rider' - not 
pay for a good but gain from its provision by others."102 Keohane has identified two separate occurrences of reciprocity which may be helpful in understanding state motivations. Specific reciprocity is used to refer to "situations in which partners exchange specified items of equivalent value in a strictly delimited sequence,"103 while diffuse reciprocity is less precise about the items or their exact equivalence. ${ }^{104}$ Although specific reciprocity is often thought to be influential in promoting cooperation, diffuse reciprocity may be just as important under certain conditions. For example, under specific reciprocity, states would be required to contribute equally to an environmental problem-solving strategy. However, states are inherently unequal, and as such may not be able to make equal contributions to an environmental problem-solving effort. Naturally, some states have a greater economic base, better technology and more resources, and are, therefore, better-equipped to 
implement proposed environmental controls. For this reason, concern over specific reciprocity is not only unwarranted, but often unfeasible for some cooperative arrangements.

On the other hand, diffuse reciprocity in environmental problem-solving can be pursued logically and to the satisfaction of most states. Often diffuse reciprocity could take the form of norms of behavior surrounding an issue; that is, actors will contribute their share not because of expected rewards, but because of the desire for continuing satisfactory overall results for the group in which they participate. ${ }^{105}$ For example, states could agree to limit their use of a public good such as water in order to fulfill the requirements of a specific environmental agreement. While states would be able to implement this goal differently and unequally, the commitment to do so would be reciprocal and go a long way towards establishing trust and the perception of absolute gains, or individual 
pay-offs. Overcoming cost objections and reducing economic uncertainty are important steps in developing state interest in environmental problem-solving. Reciprocity is one established mechanism which can distribute costs and alleviate state fears about a problem-solving effort.

\section{Political Uncertainty \& the Need for Clear Rewards:}

The presence of clear political rewards can also be important to eliminating uncertainty and engendering state participation in any cooperative effort. In environmental problem-solving, rewards in the political arena are doubly important because they are often obscure. Instead of perceiving political gains, states frequently associate high costs with participation and are reticent to commit time or resources to potentially negative outcomes. In addition, political rewards are usually described by 
Realists in terms of power ${ }^{106}$, or the ability to establish and maintain control of one state over another. ${ }^{107}$ waltz suggests that factors such as weapons acquisition, expanded territory and desire for maximizing wealth are rewards that nations seek to increase their political power. ${ }^{108}$ Thus, political power is not always a positive reward in an environmental problem-solving effort, as it does not represent an equivalent gain for all players. Furthermore, if all actors involved hold the same perception about payoffs, one state's gain becomes another's loss and causes a zero-sum game. ${ }^{109}$

Because of this view that power is the most desirable political reward, the perception of concrete political gains may be the most difficult motivator to develop in environmental problem-solving. However, there are additional political rewards which can be utilized in an environmental problem-solving effort. Membership is an important aspect of international relations. As evidenced 
in groups such as the North Atlantic Treaty Organization and the European Union, the desirability of belonging to communities of states can be an important reward. Conversely, exclusion from such arrangements can also be a motivator. Perhaps the member states of a particular environmental problem-solving effort could also be the recipients of any long-term benefits of participation, while non-participants would be excluded from those benefits. For example, promises to grant technology transfers could produce a political impetus for participation, in addition to providing a future economic benefit. As expanded upon in the section on multilateral participation, Axelrod has shown that concern over future relationships with other actors is important to states. ${ }^{110}$ Therefore, a significant source of political rewards can be found in the perception a reticent state has that the problem-solving effort will affect its relations with other states in the future; special agreements, group 
membership and improved relations are all potential gains which can be motivators for state participation.

Because they frequently appear to be intangible or nebulous, political inhibitors may be equally exacting to identify and resolve. However, reducing or eliminating political uncertainty can come from gaining initial state interest in the problem-solving effort. As will be explored in the discussion of unilateral participation, establishing a single state's desire to participate may bring about greater levels of state participation. Further, the development of widespread problem perception may also alleviate the estimation of significant political risk by eliminating the fear that other states will not be amenable to participation. Finally, the use of past successes in environmental problem-solving may also strengthen political certainty on issues where other objections do not exist. The fact that perceptions about the importance of the environment as a whole have evolved 
Bothwell, 61

to reflect state interest bodes well for decreased political risk in some environmental problem-solving efforts. 


\section{INHIBITORS \& MOTIVATORS: \\ A Model of State Response}

Scarcity of clear rewards, lack of reciprocity, and absence of threat are important inhibitors to state participation in environmental problem-solving. Conversely, establishing benefits, reciprocal arrangements and a perception of threat are positive motivators which can reduce uncertainty and gain state involvement. On many environmental issues the problem perception has been initially established; and as previously stated, many states are now aware of the hazards of pollution and the potential ramifications of wanton destruction of natural resources. However, state-centric consequences have not yet been determined on specific issue areas; without such, it remains unlikely that states will find sufficient selfinterest to participate. Reductions in scientific, economic and political uncertainties through 
identification of inhibitors and motivators can reverse this cycle. Inhibitors produce state non-participation on certain issues, and positively, they imply the methods by which participation can be encouraged. Although nonparticipation may have once been the preferred policy option, the emergence of awareness over environmental concerns, perhaps due in part to the arguments of Environmentalists, has increased overall state participation in environmental problem-solving. What is now needed is the development of factors which will motivate state participation and overcome those objections states have to participating in arrangements which appear to hold little benefit or significant cost.

The model which follows is intended as a beginning step toward this goal. The five courses of state participation and how they are influenced by inhibitors and motivators controlling uncertainty are presented. These actions are arranged on a continuum from least responsive (resistance) 
to most responsive (multilateral participation or cooperation). Between the two extremes are a more moderate negative response (inaction), a neutral stance (capitulation) and a moderate positive stance (unilateral action). This arrangement is not arbitrary; rather, it is logically implied by correlating the inhibiting and motivating factors along the same continuum from negative through uncertainty to positive as follows:

Figure 1. The Logical Relationship Between Political Courses of Action and Inhibiting or Motivating Factors

courses of Action

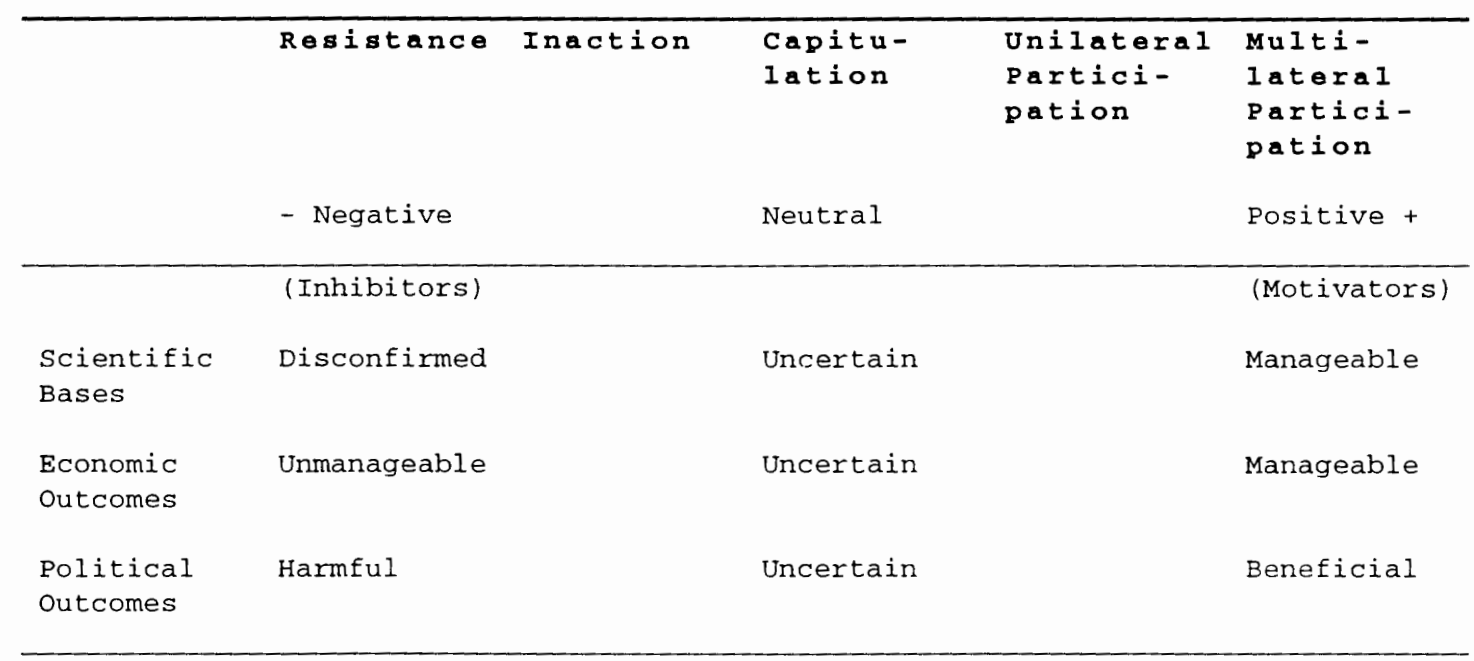


As the reader can determine from analysis of the figure, where all of the factors are negative there is a high degree of inhibition to positive action which is expressed as resistance by the actor. Where the factors are somewhat less negative, there is less inhibition and the response becomes passive inaction, rather than the more active response of resistance. In the case of a rough balance between positive and negative factors and uncertainty exists, there is a more or less neutral stance and the actor is open to capitulation in the face of strong arguments from fellow actors. Where the weight of the factors becomes more positive than negative, the actor may decide upon unilateral action in its own selfinterest. Finally, where all factors are highly positive, the state is impelled to act in concert with other actors toward an international solution to the problem and multilateral participation or cooperation occurs. In the remainder of this section, each of these courses of action 
will be examined in the light of the model presented here.

\section{RESISTANCE :}

The first type of state participation is the most negative option and is the result of key inhibitors such as ill-defined benefits or perceived high costs. Resistance implies that problem recognition has occurred, but the cost-benefit analysis is such that states are withstanding pressure from interested states or other political actors to engage in the problem-solving effort. Resistance does not intimate disinterest, but rather a strong predilection to avoid participation. Because resistance is the strongest negative response to environmental problem-solving, it is also a reflection of issues which contain the most inhibitors to state participation. Thus issues which engender resistance will require the greatest use of motivators to overcome objections. Unlike inaction, however, resistance is a 
clear decision not to participate based upon the perception of certain negative outcomes. Only in resistance is state decision-making taken to the extreme left of the model; resistance does not evidence uncertainty over future costs, instead a resistant state perceives negative outcomes that it objects to. Only the introduction of more positive information can then alter the condition of resistance into a more uncertain costbenefit analysis, ultimately paving the way for the introduction of motivators to encourage a more positive response.

Resistance often occurs despite some states perceiving a state-centric consequence, and therefore exhibiting the desire to participate. Resistance can be politically inspired and seek not only to maintain a no regrets policy for the state itself, but hope that other states will negatively follow suit and boycott participation. Because of bandwagoning, states exhibiting resistance may attempt 
to prevent the momentum of other state participation, in order to limit their own involvement. Thus, resistance can be politically motivated non-participation, which may have the effect of preventing a multilateral coordinated policymaking decision. For example, the resistance of the United States to initial negotiations on the ozone depletion issue jeopardized the entire effort until, in light of overwhelming scientific evidence, Dupont Chemical Corporation made the decision to comply with the proposed CFC ban and initiated the development of acceptable, environmentally-safe substitutes. ${ }^{111}$

Clearly resistance by powerful states can have a greater impact upon cooperative arrangements. However, many environmental problems implicate smaller, less-developed states as key players in potential problem-solving efforts. Because poverty has often necessitated policies damaging to the environment, smaller states are contributing increasingly to environmental problems. 
Costa Rica, for example, is one of the largest contributors to deforestation because of its continued conversion of forests to cattle ranching. ${ }^{112}$ Thus, the resistance of small states to cooperative agreements can also stall multilateral environmental problem-solving.

\section{INACTION :}

Environmentalists often accuse states of inaction, and therefore, justify their claims of state inadequacy in environmental problem-solving. However, there can be good reasons for continued inaction, not the least of which is the complexity of the issues-at-hand, and the unknown outcomes of many policy options. In particular, when the costs appear high and the benefits either negligible or unknown, inaction is the logical policy option in a costbenefit analysis. Inaction is one step removed from resistance; that is, the factors inhibiting participation are high, but not as high as in the situation which causes 
outright resistance to participation. In choosing inaction, states may not participate for a variety of reasons relative to uncertainty. For example, scientific uncertainty may prevent problem recognition, the first necessary condition for participation. Or, combined areas of uncertainty may allow for a limited understanding of the environmental problem to be resolved, but prevent perception of a relevant state-centric consequence from emerging.

However, unlike resistance, inaction implies an apathy toward the environmental problem-solving process; possibly the environmental problem is debated in Environmentalist literature, but concerted attempts to address the issue have either yet to result or have been ignored by states. Further, as a reflection of power politics, resistance holds more implications for continued prevention of an overall solution to a specific environmental issue than inaction, as the latter can often be overcome through 
small reductions in uncertainty. For example, inaction is the logical policy option for states when faced with a new and uncertain prospect. This was exactly the case when concerns about hazardous waste management arose in the 1960s. However, once scientific certainty over the damage created by unchecked dumping became clear, states initiated a variety of agreements to regulate this problem both domestically and internationally. In all probability, following the availability of greater amount of information and thus, certainty, states became concerned over long-term potential costs to national interest over this issue. Thus, while inaction is clearly not a positive state response, it represents a situation of uncertainty. This situation provides opportunities for Environmentalists to increase the amount of reliable information to states, thereby potentially tilting the cost-benefit analysis in favor of limited participation. Therefore, while inaction has been the basis for 
Environmentalist criticism, it also provides the starting point for harmonizing Environmentalist appeals and the policy needs of states.

\section{CAPITULATION :}

As illustrated by Canada's unilateral attempts to alter policies regarding dumping of wastes in international waters adjacent to its coastlines (an action explored in the next section), repeated attempts by individuals or small groups of states to address certain environmental issues often can gain wider state participation. Thus, capitulation represents a rough balance between a negative and positive response on the continuum. Overcoming initial objections to environmental problem-solving and establishing minimal participation can result in capitulation; through the process of bandwagoning, states will often follow suit once an initiator leads the way toward establishing new policies. Again, key to this 
whole mechanism is the need for a state-centric consequence to be presented for the instigator and for subsequent participators. However, while the statecentric consequence may be difficult to establish for the initial participant, the very fact that at least one state identifies such a consequence will engender some awareness on the part of other states. Clearly, bandwagoning can only result if either the initiator receives obvious gains from its participation, or if that state is in a position to influence the perceptions of other states. Thus, bandwagoning may be a reflection of power politics in some cases. The fact that Bangladesh is very concerned about the predicted rise in sea-level from global warming has done little to motivate others to push for a cooperative arrangement. ${ }^{113}$ Again, this points to political Realism and the need to keep an understanding of international politics in mind when arguing for environmental problemsolving. Power politics is very much an aspect of all 
international negotiations, and therefore should be remembered; gaining the interest of powerful states in environmental problem-solving is an important method of ensuring its success.

In addition to bandwagoning, the use of "side payments" to encourage participation is one method of gaining wider state involvement. Side payments are a means of overcoming objections to specific costs associated with a particular environmental problem-solving arrangement. Because equity issues appeared to predominate "behind the initial reluctance and in some cases, continuing resistance, of less-developed countries to participate in the CFC regulatory process," 114 the use of side payments became increasingly important to the negotiations on the ozone depletion issue. Other concessions for economically disadvantaged states, who perceived themselves to be greatly impacted by elimination of CFC's, had to be established prior to their consent; one of the concessions 
was the establishment of a grace period for CFC elimination until 2010.115 Eliminating this primary inhibitor was important to the larger states involved and contributed to the overall effectiveness of the entire problem-solving effort. Thus, overcoming objections, or facilitating the emergence of motivators, may become a crucial aspect of generating capitulation and establishing wider state participation.

\section{UNILATERAL PARTICIPATION:}

The fourth course of action which states can opt for is that of unilateral participation. There are many positive examples of unilateral action benefitting environment on the part of states. Environmentalists have discounted unilateral measures because they have minimal impact on the global ramifications of environmental problems. For example, it has been determined that unilateral elimination of $\mathrm{CO}_{2}$ would only have a minimal impact on 
overall global $\mathrm{CO}_{2}$ reductions:

Any benefit of a unilateral reduction in $\mathrm{CO}_{2}$ emissions by one country is therefore scaled down by a factor equal to the proportion of global $\mathrm{CO}_{2}$ emissions coming from that country, and the biggest such proportion is only $23 \%$ for the largest single emitter (the U.S.A.). ${ }^{116}$

However, individual state participation should not be immediately deprecated. While initially negligible environmentally, unilateral actions may have significant political impact. Unilateral participation is one way to gain capitulation from other states, thereby widening participation on a given environmental issue. Because of this potential, and because the advent of one state's participation indicates the presence of significant motivators, unilateral participation is viewed as a positive response to Environmentalist appeals. Further, the presence of initial state awareness over a particular issue, as is the case in unilateral participation, presents the likelihood that states will make known their 
objections to multilateral participation. Thus, it is believed that unilateral participation provides a window of opportunity for Environmentalists to gain information about state objections and overcome state uncertainties. If so, then many issues will become potential prospects for a cooperative decision-making effort. Consider, for example, the attempts of Canada at preventing water pollution off its coasts and the resulting widespread state involvement.

The Examination of Positive State Response:

A Case Study of Canada's Unilateral Problem-Solving

Following a pivotal incident which raised the awareness of the environmental consequences of oil pollution, the foundering of the Torrey Canyon off the English coastline in 1967, Canada as well as many other coastal states raised the issue of preventive measures for polluting 
activities. ${ }^{117}$ The discharge of oil from the Torrey Canyon caused large-scale pollution to Great Britain's territorial waters and ultimately helped bring about the Convention on Intervention on the High Seas in Cases of Oil Pollution ${ }^{18}$ and the Convention on Civil Liability for Oil Pollution Damage in 1969.119 These Conventions reflected the recognition by states that global measures were required to contend with the problem of humanly introduced pollutants such as oil. The parties to the Convention on Intervention agreed to:

take such measures on the high seas as may be necessary to prevent, mitigate or eliminate grave and imminent danger to their coastline or related interests from pollution or threat of pollution of the sea by oil, following upon a maritime casualty or acts related to such a casualty, which may be expected to result in major harmful consequences. ${ }^{220}$

However, despite the recent development of international law to include liability for oil pollution, Canada was dissatisfied with the measures' lack of foresight. 
Although the signatories of the Convention on Intervention agreed to preventive measures for protection of coastline and the territorial sea, these were to be taken only after the casualty had occurred on the high sea. Further, the injured state was required to consult with the other states affected by such actions, particularly the flag state or states alleged to have generated the oil. ${ }^{121}$ Canada was also displeased with the outcome of the Civil Damage Convention; "in its view, strict liability was not adequate because of the fact that the carriage of oil by sea is inherently an ultrahazardous occupation, and as such should give rise to absolute liability, with no exemptions whether in respect of natural causes or otherwise."122 In addition, Canada was concerned about the spatial Iimitations of the Civil Damage Convention. The fact that discharges in the high seas would have pollutive effects on the contiguous zones prior to affecting the territorial sea was a key consideration for 
Canada's fishing industry. Further, the fact that the limits of territorial seas differed among states gave rise to spatial inequities by "giving greater rights to those which had extended their territorial seas to the widely accepted twelve-mile limit, while those who maintained the traditional three-mile belt would not even be able to recover in respect of injury caused to fishing interests in the contiguous zone. ${ }^{123}$

Perceived inequities between flag states and coastal countries also plagued the Conventions. Canada with its lengthy coastline and close proximity to American tanker trade routes was instrumental in securing the terms of the Convention on Intervention to cover "major" damage as opposed to damage with "catastrophic" or "disastrous" consequences. ${ }^{124}$ In addition, Canada successfully opposed attempts of flag states to require the actions of coastal states to reflect the principles of the convention in their own territorial seas. And, although unsuccessful, 
Canada attempted to broaden the parameters of the Convention on Intervention to include all pollutants instead of restricting them solely to oil. ${ }^{125}$ Because of Canada's belief that the Conventions were inadequate to address its needs, the state abstained on the convention on Intervention and voted against the Civil Damage Convention; specifically, Canada determined that the two Conventions "did not pay sufficient attention to the fundamental interests of coastal states as compared with commercial interests of flag states who favored a minimum of interference."126 Instead, to augment the terms of the Conventions, Canada then amended its declaration under the "optional clause" of the statute of the International Court of Justice in 1970 to exclude:

disputes arising out of or concerning jurisdiction of rights claimed or exercised by Canada in respect of the conservation, management or exploitation of the living resources of the sea, or in respect of the prevention or control of pollution or contamination of the marine environment in marine areas adjacent to the coast of Canada. ${ }^{127}$ 
Although Canada's actions were considered a radical departure from the norm at the time of the Conventions, they were in complete accordance with the instruments of international law. Initially, Canada's actions were in line with the judgement handed down by the Tribunal in the Trail Smelter Arbitration ${ }^{128}$ in which Canada was the respondent state. The decision of the Tribunal indicated not only that Canada was liable for the damaging effects of the smelter on the territory of the plaintiff, the United states, but also that Canada must refrain from such actions which might cause further damage, thereby instituting preventive measures for future operations. In principle, this type of temporal regulation was what Canada sought in its attempts to broaden the 1969 Conventions. Once the damage from oil or other pollutants had been caused, there should be nothing preventing the injured state from adopting measures for future control of such occurrences through application of an injunction. ${ }^{129}$ 
Canada introduced additional anti-pollution legislation in 1970. Both the Act to Prevent Pollution of Areas of the Arctic Waters Adjacent to the Mainland and Islands of Canadian Arctic ${ }^{130}$ and the amended Canada Shipping Act were legislative attempts to unilaterally control pollutive acts adjacent to the Canadian territorial sea and contiguous zones. And, both Acts were significantly more stringent than the 1969 international Conventions in their definitions of polluting activities and the liabilities imposed for such actions. Specifically, pollution is defined as "the deposit of waste of any type within the Canadian Arctic," while waste is defined as any substance , which if added to the waters would alter the quality of the water "to an extent that is detrimental to their use by man or by any animal, fish or plant that is useful to man."131 The Canadian Shipping Act extended the principles of the Canadian Arctic Act to all Canadian waters and fishing zones. ${ }^{132}$ 
Much of the unilateral activity of Canada has been protested by affected states. However, where it did not produce this result, the motion has been followed by similar activities by other states, and "in the case of the continental shelf, eventually brought about a change in the law, culminating in a convention giving effect to such change. ${ }^{133}$ Thus, while Canada's policy decision may have had limited effect upon international water pollution, it captured the attention of states worldwide. Once considered extreme, through the process of bandwagoning, many states have followed suit and the concept of liability for polluting activities, i.e. the "polluter pays" principle, is now commonplace. The establishment of awareness is one potential outcome of such unilateral participation, and the development of behavioral norms, which can greatly impact environmental problem-solving, is another.

As illustrated, unilateral policymaking can have the 
effect of elevating environmental problems from issues of low priority to those of international importance. Individual state participation is clearly undertaken out of a singular perception of self-interest. An issue which inspires unilateral action at the risk of offending neighboring states must be of high importance to the initiating state. Through bandwagoning, however, it is possible that a particular issue could gain similar significance to other states. Finally, unilateral action has the benefit of creating first-mover advantage for the participant. In complex issues, where technology becomes a key factor for implementation, the first mover advantage allows the initiator to gain a greater benefit should others follow. ${ }^{134}$ For example, in the ozone depletion issue, the planned development of CFC substitutes by Dupont Chemical Corporation gave the United States an economic gain over other countries following the CFC ban. ${ }^{135}$ Ultimately, while limited in their environmental 
impact, unilateral actions can have significant political clout and are worthy of both further analysis and encouragement. In terms of the conceptual model, the Canadian Case Study can be viewed as a proactive stance by a single state to maximize its position once motivators encouraging state response were realized. That is, once there was a confirmed basis of threat in the actions of other nations, Canada took steps to assure manageable economic outcomes and beneficial political outcomes for itself. In so doing, it was helping point the way toward the possibility of similar efforts being simultaneously employed by two or more states in a multilateral approach to environmental problem-solving.

\section{MULTILATERAL PARTICIPATION OR COOPERATION:}

Realism is often criticized by Environmentalists and other Idealist-based theorists for its apparent focus on 
conflict. However, newer Realist constructs have shown optimism for cooperative arrangements and have re-examined that notion. In particular, Arthur stein illustrates the shortcomings of theories which focus solely on occurrence of either cooperation or conflict. As stein contends, "nations are neither inveterate cooperators nor defectors."136 Rather, outcomes of either cooperation or conflict are the result of the strategic choices of states engaged in a rational cost-benefit analysis. Thus, both options are aspects of states' strategic menu-for-choice, and are used to ensure survival and fulfill national interests. ${ }^{137}$ Most importantly, stein reinforces the idea that states have the capacity for cooperation; if they eschew that strategy in favor of competition or conflict, it is a reflection of the presence of factors which promote those choices in a rational cost-benefit analysis. ${ }^{138}$

Although cooperation is but one state response to 
environmental problem-solving, it is often thought to be the most effective. Because of their inherent complexity, transboundary nature and changing outcomes, environmental problems appear to require a concerted effort in order to alter their effects. As Rowlands points out:

The emergent challenges constitute a distinct category of international problems, unlike any in the past. Thus they lie beyond the scope of established diplomacy and international relations. While impinging on the strategic interests of individual nations, they are generally unsusceptible to the standard response to major threats, namely military force. Rather, they require a basically different response, with emphasis on coordination instead of confrontation. ${ }^{139}$

However, as cooperation is a type of coordinated behavior, it is not equivalent to harmony, where states would have identical interests and act concertedly to achieve those interests. ${ }^{140}$ Rather, cooperation can exist within the presence of divergent interests under certain conditions. It is these conditions that can bridge the gap between theories of Realism and Environmentalist approaches to 
problem-solving. Cooperating states attempt to coordinate their actions in order to obtain desirable outcomes; in other words, "it is anticipated that all players will accrue benefits," and that cooperation is not a zero-sum game. ${ }^{141}$ Keohane defines cooperation as the following:

cooperation requires that the actions of separate individuals or organizations - which are not in preexistent harmony - be brought into conformity with one another through a process of negotiation, which is often referred to as 'policy' coordination. Cooperation occurs when actors adjust their behavior to the actual or anticipated preferences of others, through a process of policy coordination. ${ }^{142}$

Historically states have entered into mechanisms for international cooperation such as conventions, treaties etc., to establish order in the anarchical international system and to escape suboptimal results from acting unilaterally. However, achieving cooperation can be difficult. Because of the tendency to form a Prisoner's Dilemma, ${ }^{143}$ in which the preferred strategy is to defect, 
Realism has often looked to competitive strategies as dominant behavioral tendencies. ${ }^{144}$ The Prisoner's Dilemma is so named for a scenario in which two accomplices are arrested and questioned separately leading to the choice either of defection, confessing and implicating the other in exchange for a lighter sentence, or cooperating, refusing to name the other in hope that the accomplice will do the same. Under these conditions the chances of cooperation are very slim, despite the presence of a mutual reward in the form of a minor sentence. Because Prisoner's Dilemma, in its original form, is not an iterated game, that is, it is not likely that the two prisoners will interact under the same conditions again, defection becomes the preferred option; both players have an incentive to defect no matter whether the other cooperates or defects. The preference ordering for both players is $\mathrm{DC}>\mathrm{CC}>\mathrm{DD}>\mathrm{CD}$, where $\mathrm{D}$ represents defection and $C$ represents cooperation. ${ }^{245}$ Therefore, the dominant 
strategy becomes to defect before the other prisoner can do so.

Luckily, in the real world, individual states engaged in Prisoner's Dilemma situations are not likely to confront each other only once. ${ }^{146}$ Instead, they are more apt to engage in equivalent repeated plays of the same scenario. According to Axelrod, continued interaction results in a concern for the future. It is this concern for future actions which can help to promote cooperation; a game with a future offers players higher payoffs in the long run for mutual cooperation than for mutual defection and provides a means for punishing a previous defection. ${ }^{147}$ Axelrod's work is instrumental in showing that continued interaction is what makes cooperation based on reciprocity, or an even exchange, to be possible. ${ }^{148}$ Furthermore, the more future payoffs are valued in relation to current payoffs, the less incentive there exists to defect today. ${ }^{149}$ Thus, establishing a concern for the future, what Axelrod calls 
"lengthening the shadow of the future," is important to generating a lasting cooperative arrangement where the impetus to defect remains low. ${ }^{150}$ In particular, the development of long-time horizons, regularization of the stakes involved in the arrangement, facilitation of reliable information about others' actions and availability of quick information regarding changes in others' actions are factors which can promote the incidence of cooperation and lengthen the shadow of the Euture. ${ }^{151}$

Although the shadow of the future represents a necessary, but not sufficient, condition for cooperation to emerge, concern for the future must be important enough to overwhelm attempts to defect on the present play. ${ }^{152}$ This strategy has been proven effective in computer simulations of predictive choice. Labeled TIT FOR TAT (TFT) by Axelrod, under repeated play, a TFT strategy cooperates on the first move and repeats the subsequent 
moves of the other players. Thus, TFT "is never the first to defect; it forgives an isolated defection after a single response, but is always incited by a defection no matter how good the interaction has been so far."153

Axelrod's findings are important in the context of environmental problem-solving. TFT is successful despite the presence of anarchy and state actors represented as egoists. By depicting states as egoists, i.e. those who are seeking to maximize their own payoffs, Axelrod illustrates how cooperation can occur within political Realism. ${ }^{154}$ Furthermore, Axelrod uncovers two important realities in state-centric environmental problem-solving: first, cooperation on environmental problem-solving can occur in the absence of any central authority as an enforcement mechanism; second, states will often be selfinterested, concerned with their own payoffs (absolute gains), and preoccupied with their payoffs in relation to other actors (relative gains). The presence of these 
barriers to action illustrates why Environmentalist appeals do not motivate states to act upon current environmental problem-solving approaches: because they either presume the necessity of a central authority or of altruistic actors. Axelrod also exemplifies that cooperation and a state-centric approach are compatible. In particular, the fact that environmental problem-solving is a non-zero-sum game, where one state's gain does not generate another state's loss, is critical and ensures the importance of TFT as a strategy for enhancing cooperative arrangements. This factor is significant because in zerosum situations, players have no incentive to cooperate even under iterated play, as mutual rewards do not exist. ${ }^{155}$

Gaining cooperation on environmental issues is not necessarily easy. Concerns over free ridership and division of costs are key inhibitors to gaining state participation in cooperative arrangements. Janice Stein 
examines the notion that states may often choose cooperation not to make gains, but to avoid losses. Loss avoidance occurs when the identified options promise no benefits, only costs, and the strategy chosen is the one that minimizes those anticipated costs. ${ }^{156}$ This strategy is rational under a cost-benefit analysis and is consistent with both Realist theories of international relations and Axelrod's premises about dominant behavior under conditions of multiple play. Minimizing loss has two ramifications in environmental problem-solving.

First, states will seek to better their positions relatively, by seeking a more equitable distribution of costs based upon ability to pay. This strategy is seen to have affected the negotiations over the ozone depletion problem and stalled global warming talks, where the division between the more highly industrialized countries of the North and the economically disadvantaged states of South was due to the perception of different costs 
associated with cooperation. Second, concern over free riders will affect policymaking decisions of member states. Identifying and sanctioning potential defectors is problematic for a problem-solving arrangement. Each state may seek to be a free-rider and rely upon the other participants to enforce the rules. ${ }^{157}$

However, environmental problems inherently require the application of technology and expertise, thus, the presence of incentives for cooperation are readily available. For example, larger, more technologically advanced states can compete for the first-mover advantage discussed previously. In addition, trade arrangements for the exporting of technological assistance to smaller states could provide long-lasting economic benefits for larger participants. And, despite being tempted by the possibility of free ridership, smaller states have the incentive of gaining technological expertise and economic side benefits through their participation. Most 
importantly, fear of being excluded from crucial relationships with powerful states provides a strong disincentive for defecting. ${ }^{158}$

Mutual rewards do exist in environmental problem-solving situations, despite the fact that they may sometimes be unequal; the greater the ability to eliminate uncertainty and establish clear benefits, the greater the impetus to cooperate. Thus, cooperation on environmental problemsolving is either inhibited or promoted by the factors discussed previously: introduction of clear rewards, development of reciprocity, and the perception of threat. Where these factors are lacking or absent, there is little impetus for cooperation, as the next section indicates.

Examination of Uncertainty and Inactive State Response: A Case study of Attempts at a Global Warming Initiative 
general, and global warming, in particular, are among the most important environmental problems to be addressed. However, they are also illustrative of issues containing high levels of uncertainty. Uncertainty can manifest itself in a variety of forms. Specifically, scientific, economic and political uncertainty appear to present obstacles to state participation in environmental problemsolving. Scientific uncertainty appears to prevent clear problem recognition which may lead to inaction. Economic uncertainty may lead to policy preferences in favor of competing issues, and political uncertainty often can lead to conditions of mistrust and political resistance. In this case study, each of these forms will be explored as a potential barrier to environmental problem-solving through cooperation or policy coordination.

Normally, the earth's atmosphere allows sunlight to filter through, reflecting the resulting solar energy as infrared radiation. Some of this radiation remains 
trapped in the earth's atmosphere by natural agents such as clouds. However, the introduction of human-induced gases can cause more of this radiation to be stored, and may cause a rise in the atmospheric temperature. The chief "greenhouse gas" emitted by human activities is carbon dioxide $\left(\mathrm{CO}_{2}\right)$, principally from the burning of fossil fuels (oil, natural gas, and coal) but also from the elimination of $\mathrm{CO}_{2}$ "sinks" through deforestation and other destruction of the earth's natural vegetation cover. ${ }^{159}$ This increase in greenhouse gases has, in effect, thickened the atmospheric blanket that surrounds the earth, trapping in more heat; "as a result, it has been argued that average global temperature may rise - a phenomenon also known as global warming."160

In 1988, the Intergovernmental Panel on Climate Change (IPCC) estimated that a doubling of atmospheric concentrations, calculated in terms of $\mathrm{CO}_{2}$ with other greenhouse gases, the earth's average temperature would 
rise by 2.7 to 8.1 degrees Fahrenheit by the year 2100 , or about 0.5 degrees per decade. ${ }^{161}$ Following the IPCC's announcement, climate change became a major political issue. Environmentalists began to suggest that "a series of scientific conferences during the 1980s built up a consensus that human emission of $\mathrm{CO}_{2}$ and other gases would lead to a warming of the earth's surface, with associated climatic changes that could produce substantial detrimental effects on human society."162 Further, following publicity stating the decade of the 1980 s was the hottest on record, the idea of global warming started to appear plausible. ${ }^{163}$

Subsequent Environmentalist literature indicated that "the major consequences of the phenomenon (global warming) would include flooding of coastal plains as a result of the Arctic and Antarctic icecaps melting, drought, mass extinction of flora and fauna, and economic dislocation."164 Environmentalists further argue that it 
is "extremely dangerous to continue interference with the basic planetary system of heat balance, at an everincreasing pace, when the consequences are unknown."165 And they are concerned that "by the time the impacts are clearly visible, it will be far too late to avoid extensive further changes over subsequent decades."166 However, if such a phenomenon is occurring, it seems states are far less convinced than Environmentalists of the severity of the problem; "policymakers in many countries see little reason to take difficult or costly actions to avert an unknown and perhaps distant risk."167 This attitude, in terms of the conceptual model, is indicative of states' perception of scientific, economic and political uncertainty over global warming.

Scientific Uncertainty as an Inhibitor

Translated into policy directives, scientific 
uncertainty inhibits state motivation and stifles state participation. Therefore, despite early Environmentalist statements like:

Our present knowledge gives us confidence to predict the forthcoming increase in global mean surface temperature by several degrees over the next century caused by increasing levels of atmospheric $\mathrm{CO}_{2}$ and other greenhouse gases due to human activity, ${ }^{168}$

these assertions are not borne out by the subsequent actions of states. Hence, one can conclude that states either do not agree with the Environmentalist prediction of increased global warming, or do not consider that prediction to be sufficient cause for action. In the case of global warming, there seem to be several major objections to global policy implementation. Despite initial optimism for the development of a multilateral agreement modeled after the Vienna Convention on Ozone Depletion ${ }^{169}$, a framework treaty on global warming continues to be hindered. Why? It appears states do not exhibit concrete recognition that global warming is a 
predicament mandating a global initiative. Specifically, states have been ambivalent over whether there is a problem, and consequently whether there is a need for action. ${ }^{170}$ In fact, "the most striking distinction between climate change and other environmental concerns is that the actuality of global warming is not only distant in time but fraught with uncertainty as to its probable extent and consequences."171

Because of this explanation, the presence of scientific certainty is a crucial precondition for cooperation on global warming; "international cooperation will remain elusive as long as there is a disagreement about the issue being discussed."172 The extent to which the actors hold a common perception, interpretation, and understanding of the problem is directly related to the extent of international participation, as this lessens uncertainty. ${ }^{173}$ In short, scientific uncertainty is perhaps the greatest obstacle to date impeding progress on 
any global warming problem-solving policy. Emphasis on research designed to increase knowledge of climate and to narrow uncertainties is necessary before any strong policy response can be undertaken. ${ }^{174}$ Although this stand is frustrating to Environmentalists, it is in keeping with the traditional cost-benefit analysis employed by rational policymakers, who tend to adopt a wait-and-see attitude before incurring costs in the face of uncertain outcomes.

Although attempts have been made to draw a correlation between the successful ozone depletion issue and global warming, this issue linkage has yet to materialize. The Vienna Convention and subsequent Montreal Protocol and London Amendments were a reflection of policymakers' increasing certainty over scientific facts regarding ozone depletion and CFCs as a major cause of that dissipation. The original theory that implicated CFCs was postulated by Sherwood Rowland and Mario Molina in 1974. ${ }^{175}$ During the 1970s, data collected had significant margins of error 
attached, which were so wide that countries could not consider them reliable. ${ }^{176}$ In fact, this theory was not accepted until as late as 1987; in the interim, uncertainty played a major role in preventing consensus. ${ }^{177}$ The discovery of a significant hole in the ozone layer over the Antarctic in 1985 by the British Antarctic Survey determined that the issue of ozone depletion was a definite reality. ${ }^{178}$ Further, the graphic nature of an atmospheric hole acted as catalyst to policymakers in the face of a perceived threat to national and economic security.179 By the advent of the Montreal Protocol in 1987, the level of awareness regarding the rate of ozone depletion had greatly increased. Furthermore, new scientific reports over the rate of ozone depletion had created a sense of urgency not present at the 1985 Convention:

These reports were important because they demonstrated a strong consensus among scientists and policymakers that the ozone depletion problem was 
real, that it was global in scope, and that society would have to deal with the environmental and health effects of ozone depletion for decades if not centuries. ${ }^{180}$

However, despite the evidence of ozone depletion, the causal link between CFCs and ozone depletion still remained elusive. Three contending theories - the CFC theory, a natural or dynamic theory, and the solar or oddnitrogen theory - were popular with different segments of the scientific community. ${ }^{181}$ The NASA expedition in 1987 resulted in the finding that the destruction of ozone was undoubtably caused by a chemical source of atmospheric chlorine, verifying the CFC theory. ${ }^{182}$

Finally, with the cause of ozone depletion no longer a major point of contention, scientific information was considered more reliable for policymaking decisions to begin. ${ }^{183}$ By the late 1980s, there was general acceptance both that CFCs caused the ozone hole over the Antarctic, and "that the destruction of the ozone layer would have 
serious global consequences." 184 These certainties spurred policymakers to negotiate initial problem-solving steps. Once consensus was reached, 80 countries agreed to cut out CFCs as soon as possible, with the year 2000 being the latest acceptable date. ${ }^{185}$ The protocol was further strengthened by the 1990 London Amendment and again in 1992 by the Copenhagen Amendment. Today developed states are required to phaseout all CFC use by January 1, 1996, while developing nations have until 2010 to complete their phaseout. ${ }^{186}$

Scientific accord was instrumental in achieving state participation on the ozone treaty, and "it is clear the scientific consensus on the seriousness of ozone stratospheric depletion and the link with CFCs was a major element in creating conditions for the conclusion of the Montreal Protocol."187 According to Peter M. Haas, this is one manner in which Environmentalists, especially those from the scientific community, can help move along the 
environmental problem-solving process. As demonstrated in the ozone depletion issue:

"the successful coordination of national policies to protect the ozone layer was strongly influenced by the activities of an ecological "epistemic community," a knowledge-based network of specialists who shared beliefs in cause-and-effect relations, validity tests, and underlying principled values and pursued common policy goals." 188

Therefore, scientists can have a great impact on the environmental decision-making process, by eliminating problems associated with a vague interpretation of environmental issues, they have the ability to guide states toward that process. ${ }^{189}$ The impetus for participation on the ozone depletion issue might have been significantly lowered had policymakers been presented with less evidence of scientific consensus regarding the dangers of ozone depletion; less comprehensive issues such as the acid rain debate may owe lack of state participation to poor problem definition. Further, if 
there is an absence of consensus amongst the scientific community regarding the environmental issue, perhaps the problem cannot even be politically addressed.

In such cases, Environmentalists should examine their appeal for these objections and determine the best interest-based approach for gaining state participation. The Montreal Protocol's learning package "illustrates the need to build a strong consensus within the scientific community on the nature and scope of the problem as a foundation from which to build substantive policy measures."190 In particular, there must be scientific consensus regarding the problem and a need for action. ${ }^{191}$ Ultimately, "if the scientific community is split on an issue, substantive international action is unlikely."192 In terms of the conceptual model, the lack of scientific agreement not only fails to provide a motivator for international cooperation, but introduces an inhibitor.

The fact that only twenty years ago scientists were 
convinced the world was headed for another ice age ${ }^{193}$ has naturally caused policymakers to remain skeptical about global warming in the absence of concrete proof. Although there is apparently some evidence to suggest a general warming trend, the causal link between greenhouse gas emissions and temperature increases has yet to be conclusively established. ${ }^{194}$ Although, "it is tempting to attribute the $[0.5$ degree centigrade warming of the past 100 years] to the increase in greenhouse gases. Because of the natural variation of temperature, however, such an attribution cannot now be made with any degree of confidence."195 And though the theory upon which the greenhouse phenomenon is based is accepted by a large portion of the scientific community, there are those who suggest that the temperature change could be a result of variations in solar output. ${ }^{196}$ Further, others argue that the effects of alterations in the earth's orbital pattern may be having an effect on the planet's temperature, or, 
that it may simply be that temperature fluctuations are a reflection of a high noise to signal ratio. ${ }^{197}$ Scientists have admitted that, "it will be at least 10 years before anyone will be uncategorically certain that we are experiencing greenhouse-induced global warming."198

Foiled policy attempts instigated largely by Environmentalists mark continued lack of progress on global warming problem-solving. Although the United Nations Conference on Environment and Development held in Rio de Janeiro, Brazil in June, 1992 established a limited framework convention to address climate change, it was not considered successful in terms of generating policy options to address what states only see as a potential problem. The Rio Conference was scheduled to establish what was dubbed the Precautionary Principle. This Principle held various formulations; "at the one extreme it meant that if there was a possible environmental problem not yet fully confirmed by science, one should 
come down in favor of the environment in choosing among various policy options. At the other extreme, it was held to mean that if there was any chance of environmental degradation, one must act to cut off this possibility, even if the science was weak and the costs were potentially very high."199 Further progress is doubtful, despite continued Environmentalist warnings of catastrophic consequences. If scientific uncertainty were diminished in the next few years, it is possible that states could begin to negotiate incremental policies to reduce greenhouse gas emissions. However, the global warming issue is complicated by additional forms of uncertainty which contribute to state reluctance in developing problem-solving policies.

Economic Uncertainty as an Inhibitor

If global warming is determined to be a problem, then it is also associated with great costs to states. This 
deterrent exists because the human-emitted sources of greenhouse gases are related to highly valued activities such as industrial and convenience uses. For example, many scientists state that "the dominant factor determining the build-up of carbon dioxide in the decades ahead, is the rate of burning of fossil fuels."200 Of the greenhouse gases created by human activities, $\mathrm{CO}_{2}$ is thought to be the largest contributor and the most exacting for states to reduce or eliminate. Economically and politically, eliminating its usage is a far more difficult problem than was abolishing CFCs for the ozone treaty. CFCs are both non-critical for many industrial chemical operations, and are replaceable through substitute compounds. ${ }^{201}$ The development of substitutes lowered the costs of state participation considerably; by looking at the history of the ozone layer depletion issue, it is clear that the cost of banning CFCs without substitutes was not acceptable to national governments, 
but the cost of the CFC ban with substitute chemicals, was, finally, acceptable.202 It seems, therefore that states may have been willing to cooperate on the ozone depletion issue only if substitute chemicals for CFCs were made available. ${ }^{203}$ Lessening $\mathrm{CO}_{2}$ emissions appears to involve a complete re-tooling of existing industrial infrastructure and the development of unknown alternatives; these steps are not likely to be found acceptable to states. Therefore a pivotal distinction between the ozone depletion issue and global warming compounding the problem of existent scientific uncertainty is the "fact that the ozone depletion problem is more manageable that the global warming issue. ${ }^{204}$

Perceived economic uncertainty is a result of the high costs associated with state participation in plans for reduction of greenhouse gas emissions. State participation in the problem-solving process is further complicated by the astonishing variety of daily activities 
which are thought to contribute to the generation of greenhouse gases, e.g. wood fires, dairy farming, rice growing, power generation, air travel and grass burning are several examples. ${ }^{205}$ Large economic dislocations are expected, by even the most conservative and non-coercive means of reducing the risk of global warming; it is inevitable, therefore, that industrial countries will resist constraints which impair their competitiveness and that developing countries will resist constraints which impair their growth."206 The fact that the U.S. is heavily dependent upon fossil fuels breeds "the perception, widespread in the U.S. administration and corporate sector, that the costs of reducing $\mathrm{CO}_{2}$ emissions would be very high."207 And, that $\mathrm{CO}_{2}$, the main contributor to projected atmospheric change, "comes predominantly from use of fossil fuel energy and from deforestation" does not bode well for planned reductions and subsequent treaty law. ${ }^{208}$ Accordingly, the U.S. has resisted all 
Environmentalist entreaties to participate: "the scientific uncertainties must be reduced before we commit the nation's economic future to drastic and potentially misplaced policy responses."209 Worse, U.S. participation is thought to be crucial to any comprehensive problemsolving effort ${ }^{210}$, and a simple emissions freeze was found by the International Energy Agency to be an inadequate response because world energy use is expected to increase by $50 \%$ by the year $2005 .^{211}$

In addition to the adoption of high-costs, the global warming issue would be exceedingly difficult to actually pursue given present policy alternatives. Current understandings of global warming cite many additional greenhouse gases as responsible for the warming effect. That methane, a naturally occurring greenhouse emission, is considered a large contributor, is definitely problematic for states. Swamps and marshes are the biggest sources of methane, followed by rice growing and 
cattle-raising - just maintaining current levels of atmospheric methane is suggested will lead to increased global warming even with reductions in $\mathrm{CO}_{2}$ emissions. ${ }^{212}$ Predictions such as the latter do not provide states with much impetus to address global warming. In the face of such formidable obstacles, the actions of states seem as though they would have limited effect.

At present, "the gulf between the positions of various states appears too great to allow meaningful cooperation" on global warming. ${ }^{213}$ The U.S. response is typical of a developed-state reaction to the high-risk policymaking decision global warming has required to date. In addition to defending its policy based upon uncertainties and perceived high costs, the U.S. "has argued that the Rio Convention was never intended to be more than a framework without significant commitments; questioned the sincerity of some of the OECD 'green alliance' targets and positions on resource transfers (in some cases with good reason); 
and stressed the futility of OECD action set against potential long-term growth in developing country emissions and population." 214

The typical developing state response is indicative of opposite needs. On the one hand, many developing countries may be more accepting of initial problem-solving steps on global warming; however, conversely they wish to protect their fledgling industries. A viable coalition on climate change, which would include both countries of the North and the South, would have to include commitments from the industrialized countries to stabilize, and probably begin to reduce their greenhouse gas emissions above existing agreements to phase-out CFCs; "this would be necessary both as a basic logical requirement in an abatement regime (given the current large disparities) and as a means of convincing developing countries of the sincerity of the industrialized countries involved."215 In summary, for most states the economic consequences of action on global 
warming are at present at the negative end of the response continuum, which inhibits an international cooperation effort.

Political Uncertainty as an Inhibitor

The economic costs of state participation on global warming are only marginally off-set by ill-defined benefits. Further, the situation of limited gains is further aggravated by the absence of clear rewards for all participants which creates conditions of political uncertainty. Although for some states global warming is a vital issue since it could affect their very existence as states, "for others the issues associated with poverty, budget deficits or other traditional concerns are far more pressing."216 In contrast with the Vienna Convention where states engaged in reciprocal agreements through a perceived equitable exchange, global warming holds 
equivocal gains; "there are countries that might perceive themselves as potential beneficiaries of global warming."217 Some countries such as Canada and the former Soviet Union have a much cooler climate than the rest of the globe, and accordingly, they could increase their agricultural productivity through the evolution of longer and warmer growing seasons. ${ }^{218}$ Others are concerned about the predictions of rising sea levels which could have a disastrous effect on their populations and economies. ${ }^{219}$

The perception of winners and losers does not auger well for the reduction of political uncertainty necessary to galvanize state participation on the global warming issue. ${ }^{220}$ In fact, the idea that some countries will endup losers does not provide for an exchange, much less an even one. Furthermore, political uncertainty increases the North-South divide that has occurred in this and other environmental issues. The perception of problem-solving costs is universal, but global warming costs are different 
for both the developed and the developing world; "in the industrial world the issue is one of economic cost, growth and comparative advantage; in the developing world the issue is more fundamental, entailing, delaying or even foregoing development."221 These perceptions have caused political resistance to a global warming initiative, "the fallout has exacerbated North-South suspicions, and has aroused considerable domestic pressure, particularly in India, not to compromise on basic equity perceptions or 'give in' to any Northern demands." 222 Once again, the weight of political factors is toward the negative end of the action continuum, thus inhibiting multilateral participation. 


\section{RESOLVING UNCERTAINTY:}

\section{A State-Centric Approach}

The fact that environmental problem-solving can produce uncertainty requires states to utilize incremental policymaking which can gradually lead the actors involved from the negative to the positive end of the participation continuum. Constraints are existent upon the informationprocessing capabilities of the actor leading to conditions of bounded rationality where states are unable to process all available information. ${ }^{223}$ Because uncertainty constrains the cost-benefit analysis, actors cannot maximize gains in the classic sense. ${ }^{24}$ Actors cannot compile all the available information and all possible alternatives into a rational decision-making process, thus Iimitations are imposed both by the complexity and amount of the external information and the cognitive ability to absorb that which is presented. ${ }^{225}$ Accordingly, actors 
"satisfice," choosing rational alternatives which fall within a comfortable framework of alternatives which remain certain, ${ }^{226}$ because "actors laboring under bounded rationality cannot calculate the costs and benefits of each alternative course of action on each issue. On the contrary, they need to simplify their own decision-making processes in order to function effectively at all."227 Because of these constraints, the current condition of international environmental problem-solving should remain an evolutionary process; it is necessary to have an incremental means of developing awareness over the environmental issues which are to be addressed by the political actions of states. This phase is required for the evolution of problem recognition and facilitating the onset of a state-centric approach. Further, the emergent awareness of scientific data is based upon a cumulative progression of research, and must also be assimilated incrementally. Third, overcoming the objections of 
members states which are initially struggling with a costbenefit analysis also requires incremental steps. Therefore, it is reasonable to expect that the development of effective environmental treaty law is a protracted process that can be expected to continue indefinitely. ${ }^{228}$ This evolution of regulation is not unusual in international policymaking; ${ }^{229}$ rather, it should be expected as the natural outcome of an anarchic system in which Realist actors seek to maximize gains or utility. ${ }^{230}$

In a decision-making process where preference determination is complex, maximizing expected utility does not match the notion of maximizing gains set forth by Keohane. The introduction of an uncertain prospect generates "risk aversion." 231 This concept can be simply illustrated by a situation where state $E$ must choose between $A$, an expected gain of $x ; B$, an expected loss of $q$, and $C$, an expected gain of $y$, where $x>y$; despite the fact that the expected gain of the unsure prospect is 
considerably larger than the secure C-gain, the "expected utility of the gamble is smaller than the utility of the expected outcome of the gamble."232 Thus, if risk aversion is employed in uncertain situations one can expect states to avoid risk in favor of reduced gains. Despite the fact that such a choice employed in decision-making processes is considered sub-optimal, the act of satisficing should not be utilized as justification for eliminating states Erom the problem-solving mechanism. ${ }^{233}$ Rather, satisficing increasingly indicates that clear gains must be included in the Environmentalist appeal. This inclusion will decrease states uncertainty over optimal choice decisions, and increase the ability to determine policy preferences. Therefore, in order to prevent permanent solutions which are continuously "ill-fitting and scientifically uncertain," an evolutionary approach must be utilized. ${ }^{234}$ Although an on-going problem-solving mechanism is illregarded by Environmentalists, it is mandated by the need 
to increase state participation over time, and by the absence of other positive environmental problem-solving approaches. Further, Environmentalists may presume to know what the consequences will be when they propose regulation; complex ecologies have few simple causes or simple results, Environmentalist recommendations can result in new and unexpected side effects. ${ }^{235}$ Therefore, immediate and stringent approaches may hold two considerable drawbacks; first, they certainly present obstacles to gaining state participation; second, they may create new and unexpected environmental problems. Because, "ecological interactions are myriad, beyond human cognition," 236 incrementalism remains a necessary part of generating conclusions that are "temporary, evolving, and continuously expanding and perfectible, rather than overarching and deductive as an optimal formula should be."237 However, the fact that a number of formal, international agreements have been reached shows that the 
treaty route can be sufficiently speedy and flexible to cope with high levels of uncertainty. ${ }^{238}$ For example, in response to the ozone depletion issue, the Montreal Protocol was a multilateral treaty of global magnitude and rapid response: it garnered support through the culmination of scientific data which illustrated the gravity of the problem and gained participation through a concrete message of danger to the member states; however, the actual process of problem recognition and policy implementation was incremental.

The best way to facilitate this incremental problemsolving mechanism is through the continued utilization of the Convention-Protocol process. Due to the difficulty in negotiating high-cost agreements on uncertain issues, the Convention-Protocol approach is the most effective strategy generating a progressive regulation process. As noted, this framework technique was successfully utilized on the ozone depletion issue. Despite the attempt made at 
the 1985 Vienna Convention to negotiate a protocol controlling CFCs, the "effort failed primarily due to differing economic positions among the key parties."239 Instead, a resolution was adopted calling for future negotiations on a CFC protocol. ${ }^{240}$ This strategy was effective because it kept states at the negotiating table, while allowing objections to be overcome by incremental development of certainty. In terms of the model previously presented, the process moved the actors gradually along the continuum from resistance and inaction toward multilateral cooperation. As such, the much-touted Convention on Ozone Depletion was successful because it was a "product of an incremental policy process in which past decisions and actions formed the foundation upon which the Montreal Protocol was based."241 Further, the ozone depletion issue is exemplary of the ability of states to cooperate and develop a framework treaty which will allow for more stringent regulations once 
uncertainties are resolved.

As illustrated through this analysis, global warming is unlikely to engender state participation without a reduction in scientific, economic and political uncertainty. As an environmental issue, global warming lacks the perception of threat and the support of major actors due to the uncertainties present. ${ }^{242}$ The presence of scientific certainty and improved economic and political outcomes, the products of both greater understanding of the problem and continuing negotiations, were critical to achieving agreement on the Montreal Protocol; this process has only begun on the global warming issue. ${ }^{243}$ However, these drawbacks should not deter Environmentalists from attempting to gain state participation on that issue. What it does mean is that radical attempts to gain a rapid response will likely fail. The key, then, is that the "temporary formula should be so constructed so that it calls for its own 
improvement and moves the process along."244 Further, in order to cope with the progression of science, an evolutionary approach is required; scientific data and input on global issues need to be assembled and tested before the political decisions are made. ${ }^{245}$ Environmental problems will continue to require flexible solutions, ones which are "subject to current up-dating and amendments to meet rapidly changing situations and scientifictechnological progress."246 This statement is especially true of the global warming issue, due to the uncertainties described previously.

Global warming is explicative of issues that states are reluctant to address due to lack of motivators and the anticipation of high costs. These problems can be overcome through the convention-protocol process and an incremental approach. Through the use of conventions, states have time to address key areas of scientific, economic and political uncertainty; more stringent 
regulations can be implemented later through the use of protocols. As illustrated, this process was seen to be especially effective in implementing the global initiative on ozone depletion. Therefore, "the international community will have to build a similar framework of decisions and actions that will serve as a foundation on which to base a substantive international agreement on global warming." 247 Because states vary as to where climate change fits into their political priorities, substantive policies on global warming are best approached through a process of incrementalism. In this way, the limited framework convention adopted at Rio is a positive step toward addressing global warming, because it represents a formal, international recognition of the problem and acts as an expression of concern. ${ }^{248}$ Therefore, although a proposed Global Law of the Atmosphere seems highly unlikely, lesser agreements which combine specific attainable goals with a process of 
incrementalism offer hope for a problem-solving effort. ${ }^{249}$ Despite doomsday predictions about the ramifications of global warming, Environmentalists will certainly have a better chance of generating increased participation through an incremental state-centric approach, rather than through either continued pressure to adopt more stringent requirements than states are amenable to, or by not including states in their proposals. Global warming illustrates the significance of the absence of a comprehensive approach to environmental policymaking. As such, it is exemplary of the rift between Environmentalism and Realism, which hampers efforts to address comprehensive global environmental problem-solving.

\section{CONCLUSIONS :}

State participation in environmental problem-solving can and does occur. Despite Environmentalist accusations that 
states do not address environmental issues, states have historically done so within the context of a rational cost-benefit analysis; thus, they have acted when it appeared rational and in their interest to do so, and have abstained or resisted such efforts when it did not. Gaining state participation may be evolutionary and take on an incremental approach because of the complexity of environmental problems and the uncertainty surrounding them. In order to generate state awareness, some uncertainty must be eliminated in order to foster problem recognition. Then, a state-centric consequence must be perceived or established to develop the need for state participation. This stage can most easily be obtained through the perception of threat to state interests, but can also be gained if the arrangement is uncomplicated and has little cost involved. Finally, sufficient selfinterest, the most difficult factor to develop, must be present to actually motivate state action. This stage is 
easier to establish if there is a strong threat motivator combined with high levels of certainty and low perception of unequal costs (lack of reciprocity). The less the perception of threat, the greater the need for certainty of policymaking outcomes and shared distribution of costs.

In terms of the model presented in this analysis, international cooperation requires that the participants be motivated sufficiently in terms of confirmed scientific threat, adequate economic incentives and concrete political gains. Awareness of these inhibitors and motivators are the means by which a state-centric approach can be developed and state participation in environmental problem-solving can be established and continued. Ignoring these factors will consign Environmentalist appeals to limited effectiveness, rarely motivating states to act on issues where significant objections exist. The addition of political theory to the suppositions of Environmentalism, allowing development of more realistic 
strategies for tackling environmental problem-solving, would be more appropriate and effective than the current impasse between Environmentalists and Realists. It is hoped that the approach presented in this thesis is a helpful beginning.

Future research is necessary for the development of a comprehensive theoretical approach to global environmental problem-solving. In particular, a greater study of individual issues in terms of potential inhibitors and motivators must be initiated in order to appeal more effectively to state interests in problem-solving efforts. Further study of the perception of costs and benefits in environmental problem-solving may also yield important insights into gaining state interest on specific issues. And, where objections to participation exist, increased development of methods of eliminating criticism must be instigated in order to obtain more favorable state responses. Further, an in-depth historical examination of 
successful and unsuccessful environmental problem-solving efforts in relation to the action continuum used in this study would provide useful information for future attempts at cooperation. In addition, issue linkage studies could prove valuable in terms of minimizing the presence of inhibitors and gaining state confidence through past positive experiences. Finally, on issues which remain stymied due to a lack of participation, the development of alternative strategies would assist in gaining at least a limited response. For example, if a global warming initiative remains too costly for global state participation, encouragement of state inclusion in global warming research, one means of establishing certainty and minimizing costs, could be helpful in gaining future response. There is optimism for global environmental problem-solving. A rapprochement can be made between the appeals of Environmentalism and the realities of political structures best understood by Realism. The key lies in 
BothweII, 137

the pursuit of a state-centric approach. 


\section{NOTES}

1 For purposes of this paper, Realism is characterized by an anarchic international system made up of independent, sovereign nation-states. A more complete definition follows in a later section. For a comprehensive discussion of Realism see: Kenneth N. Waltz, Man, the State, and War: A Theoretical Analysis (New York: Columbia University Press, 1959); Hans J. Morgenthau, Politics Among Nations: The Struggle for Power and Peace, 5 th ed., (New York: Alfred A. Knopf, 1973); Kenneth N. Waltz, Theory of International Politics (Reading, Mass: Addison-Wesley, 1979); Robert Gilpin, War and Change in World Politics (Cambridge: Cambridge University Press, 1981); Robert O. Keohane, ed., and Its Critics (New York: Columbia University Press, 1986).

2 Idealism is associated primarily with the Wilsonian era when attempts to forge a peaceful world order based upon a just ideal culminated in the establishment of institutions such as the League of Nations. See for example, Terry Nardin, Law, Morality and the Relations of States (Princeton: Princeton University Press, 1983).

3 T. O'Riordan, Environmentalism (London: Pion Limited, 1976), 28. According to O'Riordan, Environmentalism further:

seeks a reformation of national income accounts in favor of some kind of measure of economic and social well-being; it aims to substitute a love of humanity, companionship, a concern for posterity, and the joy of natural experience for the persistent and widespread exploitation of people and the land, the desire for monetary reward, materialism, and striving 
for status; it hopes to alter institutional forms and procedures by replacing corporate hegemony, bureaucratic discretion and routinization with radical proposals for humanscale cooperative enterprise, and for consultation and participation; and it endeavors to encourage each one of us to recognize the ambiguities and inconsistencies of our beliefs and actions and to seek congruence.

4 For a discussion of Transcendentalist influence on Environmentalism, see: T. O'Riordan, Environmentalism (London: Pion Limited, 1976), 3-4, and Christopher Manes, Green Rage: Radical Environmentalism and the Unmaking of Civilization (Boston: Little, Brown and Company, 1990), 246 .

5 Robert C. Paehlke, Environmentalism and the Future of Progressive Politics (New Haven: CT: Yale University Press, 1989), 29.

6 George Perkins Marsh has been credited with developing the modern concept and definition of ecology: "the study of the interrelationships between organisms and environment." stated in: Clifton E. Wilson, "Environmental Policy and International Law," In Environmental Politics, ed. Stuart S. Nagel (New York: Praeger Publishers, 1974), 103. For a discussion of environmental concern and subsequent activism in the early 1970s, see: Michael Allaby, The Eco-Activists: Youth Fights for a Human Environment (London: Charles Knight Publishing, 1980); and Donald Worster, Nature's Economy: The Roots of Ecology (Garden City: NY: Anchor Press, 1979).

7 Paehlke, 28 .

8 O'Riordan, iv. For a discussion of the expansion of early Environmentalism, see the following: L. R. Brown, $A$ World Without Borders (New York: Random House, 1972); J. 
K. Galbraith, Economics and the Public Purpose (Boston: Houghton-Mifflin, 1973); E. F. Schumacher, Small is Beautiful: A study of Economics As if People Mattered (London: Abacus, 1973); D. C. Pirages and P. R. Ehrlich, Ark II: Social Response to Environmental Imperatives (San Francisco: Freeman, 1974); and K. E. F. Watt, The Titanic Effect: Planning for the Unthinkable (New York: Dutton, 1974).

9 Ecocentrism is defined as: "viewing man as a part of a global ecosystem, and subject to ecological and systems laws. These, and the demands of an ecologically-based morality, constrain human action, particularly through imposing limits to economic and population growth. There is also a strong sense of respect for nature in its own right, as well as for pragmatic 'systems' reasons." Stated in: David Pepper, The Roots of Modern Environmentalism (New York: Routledge, 1984), 237.

10 In contrast with Ecocentrism, Technocentrism: "believes unrestrainedly that man will always solve environmental problems and achieve unlimited growth (cornucopians), or, more cautiously, that by careful economic and environmental management they can be negotiated (the accommodators). In either case, considerable faith is placed in the ability and usefulness of classical science, technology, conventional economic reasoning (e.g. cost-benefit analysis), and their practitioners." Stated in: Pepper, 241.

11 Pepper discusses the classification of Environmentalism into belief systems and social explanations, e.g. Functionalist/Pluralist and Marxist explanations. See: Pepper, 27.

12 Manes, 140. The term Deep Ecology is derived from Arne Naess's paper, "The Shallow and Deep, Long-Range Ecology Movement."

13 Ibid., 143. 
14 Donella H. Meadows et al., Limits to Growth (New York: Universe Books, 1972).

15 John C. Garnett, "States, State-Centric Perspectives, and Interdependence Theory," in Dilemmas of World Politics: International Issues in a Changing World, ed. John Baylis and N. J. Rengger (Oxford: Clarendon Press, 1992), 64 .

\section{Ibid., 375.}

17 Thomas Thorson, A History of Political Theory, 4th ed., (Hinsdale, IL: The Dryden Press, 1973), 244.

18 Robert 0 . Keohane, "Theory of World Politics: Structural Realism and Beyond," in Political Science: The State of the Discipline, ed. Ada W. Finifter (Washington, DC: American Political Science Association, 1983), 126.

19 Jessica Tuchman Mathews, "The Environment and International Security," in World Security: Challenges for a New Century, 2nd ed., ed. Michael T. Klare and Daniel C. Thomas (New York: St. Martin's Press, 1994): $274-275$.

20 Organization for Economic Co-operation and Development. Economic and Ecological Interdependence: A Report on Selected Environment and Resource Issues (Paris: Organization for Economic Co-operation and Development, 1982), 2.

21 Robyn Eckersley, Environmentalism and Political Theory: Toward an Ecocentric Approach (New York: State University of New York Press, 1992), 49.

22 Garrett Hardin, "The Tragedy of the Commons," Science, vol. 162, (1968): 1243-1248.

23 Hardin introduced the concept of carrying capacity, which asserts that the earth can only contain a limited 
amount of the effect caused by humanity. His fundamental work was largely responsible for the development of ethics and morality in Environmentalism. See: O'Riordan and Pepper for a complete analysis of Hardin's contribution.

24 Mathews, 27.

25 For a definition of environmental interdependence, see: Barry Commoner, The Closing Circle (New York: Knopf Publishers, 1971), 33. The concept of interdependence both as it is utilized by Environmentalists and in terms of a more Realist explanation is explored more thoroughly in this paper.

26 Eckersley, 50 .

27 Ibid., 34 .

28 Ibid., 49.

29 See for example, James Rosenau, "Environmental Challenges in a Turbulent World," in the State and Social Power in Global Environmental Politics, ed. Ronnie D. Lipschutz and Ken Conca (New York: Columbia University Press, 1993), 71-93, for a discussion of levels of analysis and different political relationships as they relate to the environment.

30 Eckersley, 168.

31 Ibid., 169.

32 Mathews, 287.

33 Renner, Michael, National Security: The Economic and Environmental Dimensions (Washington, DC: Worldwatch Institute, 1989), 64.

34 Reitz, Charles $R$, "Sovereignty and Morality in International Affairs," in Political Theory Today, ed. 
David Held (Stanford: Stanford University Press, 1991), 250 .

35 Eckersley, 170.

36 Ibid., 172.

37 Ibid.

38 Waltz, Kenneth, Theory of International Politics (New York: MCGraw-Hill Publishing Co., 1979), 139.

39 Ibid., 141.

40 Ibid., 109.

41 Ibid., 145.

42 Ibid.

43 Renner, 64.

44 Robert O. Keohane, Peter M. Haas, and Marc A. Levy, "Improving the Effectiveness of International Environmental Institutions," in Institutions for the Earth: Sources of Effective International Environmental Protection, ed. Peter M. Haas, Robert 0 . Keohane, and Marc A. Levy, (Cambridge: The MIT Press, 1993), 415. 45 Reitz, 250.

46 O'Riordan, 26-35.

47 Eckersley, 170.

48 See: Harold and Margaret Sprout, "Public Policy and Environmental Crisis: what Role for Political Scientists?" Policy Studies Journal 1 (Summer, 1973): 195; and Peter G. Stillman, "Ecological Problems, Political Theory and Public Policy," Environmental Politics, ed. Stuart S. Nagel (New York: Praeger 
Publishers, 1974), 49-60.

49 See Environmentalist literature cited above for specific examples of the absence of policymaking directives. In addition, see: Steve Breyman, "Knowledge as Power: Ecology Movements and Global Environmental Problems," in The state and Social Power in Global Environmental Politics, ed. Ronnie D. Lipschutz and Ken Conca (New York: Columbia University Press, 1993), 124157, for a characterization of the Environmental movements' activities.

50 For a sampling of Environmentalists advocating the alteration of the international system, and/or the removal of the state as the dominant political actor, see: Barry Commoner, The Closing Circle (New York: Alfred A. Knopf, 1971); Lynton K. Caldwell, "The Changing Structure of International Policy: Needs and Alternatives," in Environmental Policy: Concepts and International Implications, ed. Albert E. Hutton and Daniel H. Henning (New York: Praeger Publishers, 1973, 134-142; Richard A. Falk, "Environmental Policy as a World Order Problem," in Environmental Policy: Concepts and International Implications, ed. Albert E. Hutton and Daniel H. Henning (New York: Praeger Publishers, 1973), 142-152; William Ophuls, "Leviathan or Oblivion?," in Toward a Steady-State Economy, ed. Herman E. Daly (San Francisco: W. H. Freeman, 1973); Ann Hawkins, "Contested Ground: International Environmentalism and Global Climate Change," in The state and Social Power in Global Environmental Politics, ed. Ronnie D. Lipschutz and Ken Conca (New York: Columbia University Press, 1993), 221245; Karen Liftin, "Eco-regimes: Playing Tug of War with the Nation State," in The State and Social Power in Global Environmental Politics, ed. Ronnie D. Lipschutz and Ken Conca (New York: Columbia University Press, 1993), 94-118; Ronnie D. Lipschutz and Ken Conca, "(Re) Constructing the Global Environment: Global Ecological Interdependence and Political Contestation," in The state and Social Power in Global Environmental Politics, ed. Ronnie D. Lipschutz and Ken Conca (New York: Columbia University Press, 1993), 119-123; Robert C. Johansen, 
"Building World Security: The Need for strengthened International Institutions," in world security: Challenges for a New Century, ed. Michael T. Klare and Daniel C. Thomas, 2nd ed., (New York: St. Martin's Press, 1994), 372-398; Jessica Tuchman Mathews, "The Environment and International Security," in World Security: Challenges for a New Century, ed. Michael T. Klare and Daniel C. Thomas, 2nd ed., (New York: St. Martin's Press, 1994), 274-289.

51 For a complete discussion of the contest between nation-states and other actors, in particular nongovernmental organizations, see: Ann Hawkins, 221-245.

52 Harold and Margaret Sprout, 194.

53 Waltz, 139.

54 See: Waltz, Chapters 3 and 7 for a look at the Structural Realist approach.

55 For a discussion of Neorealism, see: Robert 0. Keohane, "Realism Neorealism and the study of World Politics," Neorealism and Its Critics, ed. Robert 0. Keohane (New York: Columbia University Press, 1986), 126. Also, see: Barry Buzan, Charles Jones and Richard Little, The Logic of Anarchy: Neorealism to Structural Realism (New York: Columbia University Press, 1993), 1966, for a comparison.

56 Eor a description of Classical Realism, see: Hans $J$. Morgenthau, Politics Among Nations: The Struggle for Power and Peace, brief edition, rev., Kenneth W. Thompson (New York: McGraw-Hill, 1993), 3-24.

57 Waltz, 141.

58 Ibid., 109.

59 Ibid., 145. 
60 Arthur Stein, Why Nations Cooperate: Circumstance and Choice in International Relations (Ithaca: NY: Cornell University Press, 1990), 5-7.

61 Waltz, 139.

62 Robert 0 . Keohane, After Hegemony: Cooperation and Discord in the World Political Economy (Princeton: N. J.: Princeton University Press, 1984), 122.

63 Ibid.

64 Ibid., 123.

65 For a discussion of the existence of order in the international system, see: Stein, Chapter 2. Eor a definition of the order-seeking behaviors of states, see: Gary L. Scott and Craig I. Carr, "Are States Moral Agents," Social Theory and Practice, 12 (1), (Spring 1986): 86-94.

66 Stein, 29-30.

67 Richard Cooper, The Economics of Interdependence (New York: MCGraw-Hill, 1968), 152. Cooper developed the original terms of sensitivity and vulnerability. These concepts have been expanded upon by Robert 0 . Keohane and Joseph $S$. Nye in Power and Interdependence: World Politics in Transition (Boston: Little, Brown and Company, 1977), 12.

68 Keohane and Nye, 13.

69 Ibid.

70 Ibid.

71 A definition of reciprocity will be discussed later in this paper. Eor a more complete discussion, see Robert o. Keohane, "Reciprocity in International Relations," International Organization 40 (1), (Winter 1986): 1-28. 
72 Waltz, 159.

73 Ibid.

74 Paehlke, 3 .

75 A problematique is a series of problems which are so interrelated that the only way to address them is together.

76 Johansen, 378 .

77 James N. Rosenau, "Thinking Theory Thoroughly," The Scientific Study of Foreign Policy (London: Frances Pinter, 1980), 21.

78 Ibid., 22.

79 Gerhard von Glahn, Law Among Nations: An Introduction to Public International Law, 6th ed., (New York: Macmillan Publishing Co., 1992), 12.

80 Ibid., 138.

81 Ibid., 12, 136.

82 Matthew Paterson and Michael Grubb, "The International Politics of Climate Change," International Affairs 68 (2), (1992): 301 .

83 Index to Multilateral Treaties (Cambridge: MA: Harvard Law School, 1965), 24.

84 James Barros and Douglas M. Johnston, The International Law of Pollution (New York: Eree Press, 1974), 177-195.

85 Compiled in: Register of International Treaties and other Agreements in the Field of the Environment 
(Nairobi: United Nations Environment Programme, 1991).

86 Jessica Tuchman Mathews, "Redefining Security," Foreign Affairs 68 (Spring 1989): 164.

87 Soroos, Marvin S. "The Evolution of Global Regulation of Atmospheric Pollution," Policy Studies Journal 19 (2), (Spring 1991): 118.

88 Robert Axelrod, The Evolution of Cooperation (New York: Basic Books, 1984), 20.

89 Keohane, "Reciprocity in International Relations," 18.

90 Axelrod, 20.

91 Henry Theil, Optimal Decision Rules for Government and Industry (Chicago: Rand McNally \& Co., 1964), 23.

92 Ibid.

93 Ibid.

94 Ibid., 24

95 William Zartman, "International Environmental Negotiation: Challenges for Analysis and Practice," Negotiation Journal (April 1992): 116.

96 Stahrl w. Edmunds, "Environmental Policy: Bounded Rationality Applied to Unbounded Ecological Problems," Environmental Policy Formation (1984): 200.

97 Ian H. Rowlands, "Ozone Layer Depletion and Global Warming: New Sources for Environmental Disputes," Peace and Change 16 (3), (July 1991): 269.

98 Waltz, 88

99 Kluwer Law and Taxation Publishers, International 
Environmental Law: Primary Materials, ed. Michael R. Molitor (Boston: Kluwer Law and Taxation Publishers, 1991), 451 .

100 Keohane, "Reciprocity in International Relations," 12 .

101 Ibid., 8

102 Ibid.

103 Ibid., 4

104 Ibid.

105 Ibid., 20

106 Morgenthau, 5.

107 Ibid., 11.

108 Waltz, Chapter 5.

109 Ibid., 129.

110 Axelrod, 174

111 "Dupont Position Statement on the ChlorofluorocarbonOzone-Greenhouse Issues," Environmental Conservation 13, (Winter 1986): 363-364. For analysis see: Sherwood F. Rowland and Mario J. Molina, "Ozone Depletion: 20 Years After the Alarm," Chemical and Engineering News, 15 August 1994 .

112 Barbara J. Bramble and Gareth Porter, "NonGovernmental Organizations and the Making of US International Environmental Policy," in The International Politics of the Environment: Actors, Interests, and Institutions, ed. Andrew Hurrell and Benedict Kingsbury (Oxford: Clarendon Press, 1992), 344. 
113 Wilfred Beckerman, "Global Warming and International Action: An Economic Perspective," in The International Politics of the Environment: Actors, Interests, and Institutions, ed. Andrew Hurrell and Benedict Kingsbury (Oxford: Clarendon Press, 1992), 266.

114 Kerry Krutilla, "Unilateral Environmental Policy in the Global Commons," Policy Studies Journal 19 (2), (Spring 1991): 126.

115 Pamela Zurer, "Tighter CFC Substitute Controls Found Feasible," Chemical and Engineering News, 13 March 1995, 8 .

116 John Pezzey, "Analysis of Unilateral $\mathrm{CO}_{2}$ Control in the European Community and OECD," The Energy Journal 13 (3): 166 .

117 L. C. Green, "International Law and Canada's AntiPollution Legislation," Oregon Law Review 50 (3), (Spring 1971): 469 .

118 Convention on Intervention on the High Seas in Cases of Oil Pollution, Brussels (opened for signature Nov. 29, 1969), Stated in: International Legal Materials 9 (1970): 25.

119 Convention on Civil Liability for Oil pollution Damage, Brussels, (opened for signature Nov. 29, 1969), Stated in: International Legal Materials 9 (1970): 45.

120 Convention on Intervention, art I (2), Stated in: International Legal Materials 9 (1970): 26.

121 Green, 471.

122 Ibid., 475.

123 Ibid. 
124 Ibid., 472.

125 Ibid.

126 Ibid., 476.

127 Canadian Declaration Concerning the Compulsory Jurisdiction of the International Court of Justice, Stated in: International Legal Materials 9 (1970): 598.

128 Trail Smelter Arbitration (United States V. Canada) Stated in: Green, 475.

129 Ibid., 478.

130 Act to Prevent Pollution of Areas of the Arctic Waters Adjacent to the Mainland and Islands of the Canadian Arctic, Stated in: International Legal Materials 9 (1970): 543.

131 Act to Prevent Pollution of Areas of Arctic Waters Adjacent to the Mainland and Islands of the Canadian Arctic, Stated in: International Legal Materials 9 (1970): 543-544.

132 Green, 488.

133 Ibid.

134 Pezzey, 161. The first-mover advantage is the term used for describing the benefits gained by the first actor to participate in an activity which is later copied by others.

135 Peter M. Morrisette, "The Montreal Protocol: Lessons for Formulating Policies for Global Warming," Policy Studies Journal 19 (2), (Spring 1991): 154.

136 Stein, 173. 
137 Ibid.

138 Ibid.

139 Rowlands, 267.

140 Robert Axelrod and Robert O. Keohane, "Achieving Cooperation Under Anarchy: Strategies and Institutions" world Politics 38 (October 1985): 226.

141 Rowlands, 268.

142 Keohane, After Hegemony, 51.

143 R. Duncan Luce and Howard Raiffa, Games and Decisions (New York: Wiley), 94-95.

144 See for example: Waltz, 105-107.

145 Axelrod and Keohane, 229.

146 Joanne Gowa, "Anarchy, Egoism and Third Images: The Evolution of Cooperation and International Relations," International Organization 40 (1), (Winter 1986): 169.

147 Axelrod and Keohane, 232.

148 Axelrod, 125.

149 Ibid., 13

150 Ibid., 126.

151 Axelrod and Keohane, 233.

152 Gowa, 170.

153 Axelrod, 46.

154 Gowa, 175. 
155 Ibid., 177.

156 Janice Stein, "International Co-operation and Loss Avoidance: Framing the Problem," International Journal (Spring 1992): 204 .

157 Axelrod and Keohane, 235.

158 Ibid., 247.

159 William $W$. Kellogg, "Carbon Dioxide and Climate Changes," in Global Climate Change: Human and Natural Influences, ed. S. Fred Singer (New York: Paragon House Publishers, 1989): 40 .

160 Rowlands, 264.

161 Intergovernmental panel on Climate Change, IPCC Gazette 1, (June 1989): 4-5.

162 Paterson and Grubb, 293.

163 Ibid., 294.

164 David Zachary Kaufman, "The Greenhouse Effect: Available and Needed Laws and Treaties," UCLA Journal of Environmental Law 9 (1991): 219.

165 Paterson and Grubb, 297.

166 Ibid.

167 Ibid.

168 Andrew A. Lacis, "Climate From a Modeling point of View: In Reply to Comments by H. W. Ellsaesser," in Global Climate Change: Human and Natural Influences, ed. S. Fred Singer (New York: Paragon House Publishers, 1989): 81 . 
169 Vienna Convention for the Protection of the Ozone Layer (done March 22, 1985), Stated in: International Legal Materials 26 (6), (1987): 1516.

170 Morrisette, 159.

171 Eliot L. Richardson, "Climate Change: Problems of Law-Making," in The International Politics of the Environment: Actors, Interests, and Institutions, ed. Andrew Hurrell and Benedict Kingsbury (Oxford: Clarendon Press, 1992), 168.

172 Stephan Haggard and Beth A. Simmons, "Theories of International Regimes," International Organization 41 (Summer 1987): 511.

173 Rowlands, 278.

174 Paterson and Grubb, 299.

175 Mario J. Molina and F. S. Rowland, "Stratospheric Sink for Chloroflouromethanes: Chlorine Atom-Catalyzed Destruction of Ozone," Nature, 28 June 1974, 810-812.

176 Rowlands, 279.

177 Ibid.

178 Ibid., 280.

179 Morrisette, 154.

180 Ibid.

181 Rowlands, 279.

182 David Lindley, "Ozone Hole Deeper Than Ever," Nature, 8 October 1987, 473.

183 Rowlands, 280. 
184 Richardson, 168.

185 Tim Radford, "80 Nations Agree to Phase Out CFCs by End of Century," The Independent (London), September 23, 1989,8 .

186 zurer, 8. For a complete description and analysis of the agreements on the ozone depletion issue, see: Richard E. Benedict, Ozone Diplomacy: New Directions in Safeguarding the Planet (Cambridge: MA: Harvard University Press, 1991).

187 Albert weale, The New Politics of Pollution (New York: St. Martin's Press, 1992), 196.

188 Peter M. Haas, "Banning Chlorofluorocarbons: Epistemic Community Efforts to Protect stratospheric Ozone" International Organization 46 (1), (Winter 1992): 187. For more information about the epistemic community and its pivotal role in environmental problem-solving, see: Institutions for the Earth: Sources of Effective International Environmental Protection, ed., Peter $M$. Haas, Robert $O$. Keohane, and Marc A. Levy (Cambridge: MA:, The MIT Press, 1993).

189 Haas, 187.

190 Morrisette, 159.

191 Ibid.

192 Ibid.

193 F. W. W. Dilke and D. O. Gough, "Solar Mixing: The Cause of Ice Ages and a Lack of Neutrinos?" Nature, 1 December 1972, 293.

194 Rowlands, 280.

195 Richard A. Kerr, "Greenhouse Skeptic Out in the 
Cold," Science 246, (December 1989): 1118-1119.

196 Rowlands, 280.

197 Ibid.

198 E. William Colglazier, "Scientific Uncertainties, Public Policy, and Global Warming: How Sure is sure Enough?" Policy Studies Journal 19 (2), (Spring 1991): 70 .

199 Morrisette, 155.

200 Michael Grubb, "The Greenhouse Effect: Negotiating Targets," International Affairs 66 (1), (1990): 71.

201 Morrisette, 157.

202 Rowlands, 270.

203 Ibid., 271.

204 Morrisette, 157.

205 Richardson, 168.

206 Ibid.

207 Paterson and Grubb, 302.

208 Ibid., 294.

209 Stephen H. Schneider, Global Warming: Are We Entering the Greenhouse Century? (San Francisco, CA: Sierra Club Books, 1989), 24.

210 Karen Schmidt, "How Industrialized Countries Are Responding to Global Climate Change," International Environmental Affairs 3, (Fall 1991): 208. 
211 Colglazier, 65.

212 Grubb, 71-72.

213 Paterson and Grubb, 304.

214 Ibid., 305.

215 Ibid.

216 Paterson and Grubb, 295.

217 Morrisette, 157.

218 Ibid., 158.

219 Paterson and Grubb, 295.

220 Morrisette, 157.

221 Ibid.

222 Paterson and Grubb, 299.

223 Herbert A. Simon, Models of Bounded Rationality, vol. 2, (Cambridge: MIT Press, 1982), 162.

224 Keohane, After Hegemony, 111.

225 Ibid., 112.

226 Simon, 168. Simon defines satisficing as choosing a rational course of action through bounded rationality. One cannot possibly choose from all possible alternatives rationally, and therefore, states must satisfice, choosing the best alternative from reasonable choices and limited abilities.

227 Keohane, After Hegemony, 115. 
228 Soroos, 119.

229 Ibid.

230 Axelrod, 20.

231 Theil, 25.

232 Ibid.

233 See: Edmunds, 193-194

for a discussion of probabilistic decision-making.

234 Zartman, 116.

235 Edmunds, 193.

236 Ibid., 199.

237 Zartman, 116.

238 Peter S. Thatcher, "International Agreements and Cooperation in Environmental Conservation and Resource Management," Evaluation Review 15 (1), (February 1991): 34 .

239 P. H. Sand, "Protecting the Ozone Layer: The Vienna Convention is Adopted," Environment 27 (5): 20.

240 Morrisette, 154 .

241 Ibid., 158.

242 Morrisette, 156.

243 Ibid.

244 Zartman, 116. 
245 Geoffrey Palmer, "New Ways to Make International Environmental Law," The American Journal of International Law 86 (259): 263.

246 Sand, 37.

247 Morrisette, 158 .

248 Grubb, 70 .

249 Morrisette, 158. 